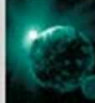

Geophysical Prospecting

\title{
Integrated Geophysical and Hydromechanical Assessment for CO2 Storage: Shallow Low Permeable - Reservoir Sandstones
}

\begin{tabular}{|r|l|}
\hline Journal: & Geophysical Prospecting \\
\hline Manuscript ID & GP-2015-0062.R2 \\
\hline Manuscript Type: & Special Issue \\
\hline Date Submitted by the Author: & $19-J a n-2016$ \\
\hline Complete List of Authors: & $\begin{array}{l}\text { Falcon-Suarez, Ismael; National Oceanography Centre, Southampton, } \\
\text { Marine Geoscience Research Group } \\
\text { North, Laurence; National Oceanography Centre, Southampton, Marine } \\
\text { Geoscience Research Group } \\
\text { Amalokwu, Kelvin; University of Southampton, Geology and Geophysics } \\
\text { Best, Angus; National Oceanography Centre, Southampton, Marine } \\
\text { Geoscience Research Group; }\end{array}$ \\
\hline Keyword: & \begin{tabular}{l} 
Electrical resistivity, Seismic, Permeability \\
\hline
\end{tabular} \\
\hline
\end{tabular}




\title{
Integrated Geophysical and Hydromechanical Assessment for $\mathrm{CO}_{2}$ Storage: Shallow Low Permeable - Reservoir Sandstones
}

\author{
By \\ Ismael Falcon-Suarez ${ }^{1}$ \\ Laurence North ${ }^{1}$ \\ Kelvin Amalokwu ${ }^{1,2}$ \\ $\&$ \\ Angus Best ${ }^{1}$ \\ (1) National Oceanography Centre, University of Southampton Waterfront \\ Campus, European Way, Southampton, SO14 3ZH, UK \\ University of Southampton, National Oceanography Centre \\ Southampton, Southampton, SO14 3ZH, UK \\ Manuscript submitted to:

\section{Geophysical Prospecting}

Special Issue "Advances in Rock Physics"

Date: August, 2015 
Formatted: Font: Italic

Formatted: Font: Italic

Formatted: Font: Italic

Formatted: Font: Italic

Formatted: Font: Italic

Formatted: Font: Italic

Formatted: Font: Italic

Formatted: Font: Italic

Formatted: Font: Italic for both fluids. Comparing the experimental results to theoretical predictions, we found that Gassmann's equations explain $V_{p}$ at high and very low $\mathrm{CO}_{2}$ saturations, while bulk modulus yields results consistent with White and Dutta-Odé model 
predictions. This is interpreted as an heterogeneous distribution of the two pore fluid phases, corroborated by electrical resistivity tomography images. The integration of laboratory geophysical and hydromechanical observations on representative shallow low permeable - sandstone reservoir allowed us to distinguish between pure geomechanical responses and those associated with the pore fluid distribution. This is a key aspect in the understanding of $\mathrm{CO}_{2}$ injection effects in deep geological reservoirs associated with carbon capture and storage practices.

Key words: seismic velocity, attenuation, electrical resistivity, permeability, $\mathrm{CO}_{2}$ injection, reservoir geophysics. 


\section{Introduction}

Atmospheric concentrations of carbon dioxide $\left(\mathrm{CO}_{2}\right)$ have increased dramatically since the end of the nineteenth century, owing chiefly to increased burning of fossil fuels by humans, but also to steel works, cement factories and chemical plants. It is well accepted that, to date, the most realistic leading mitigation strategy is Carbon Capture and Storage (CCS, IPCC 2005). CCS technologies involve the sequestration of $\mathrm{CO}_{2}$ into deep brine saturated geological formations, specially selected for such massive-scale storage. While the concept is a promising one, uncertainties and risks remain a matter of concern, especially with regard to public acceptance related to induced overpressure from $\mathrm{CO}_{2}$ injection, such as seismicity (earthquakes and landslides) or leakages to shallower aquifers. So, it is of crucial importance to develop methods and monitoring tools to accurately map the subsurface $\mathrm{CO}_{2}$ plume evolution (Shi et al. 2007).

Geological reservoirs are commonly complex both structurally and stratigraphically, and can respond to $\mathrm{CO}_{2}$ injection both geochemically (inducing dissolution/precipitation reactions especially important in the presence of carbonates which can lead to porosity reduction (Gaus 2010)) and geomechanically (induced pore pressure build-up resulting in dilatations in loose sand formations, or fractures in tight reservoir formations (Rutqvist 2012)). When injected, $\mathrm{CO}_{2}$ (whether gas, liquid or supercritical) may trigger various physical phenomena as a result of pressure and temperature gradients, and chemical disequilibria (Gaus 2010). These coupled phenomena, so called Thermal-Hydro-Mechanical-Chemical coupled processes (THMCs), need to be modelled accurately using 3D earth models of storage sites constrained by field and laboratory data, as stated in the European Directive 2009/31/EC. In this regards, many laboratory tests have been carried out 
since the early days of CCS using representative rock samples of the reservoir site target formation to further analyse and interpret the different trapping mechanisms related to injection-storage issues (Burnside and Naylor 2014). Because seismic surveys represent the most widespread technique to map and monitor the advance of the subsurface $\mathrm{CO}_{2}$ plume (Chadwick et al. 2010; Chadwick et al. 2004; Xue and Lei 2006), the experimental works focus preferentially on the analysis of seismic properties of reservoirs from elastic wave propagation through water- $\mathrm{CO}_{2}$ saturated rock samples (Chen et al. 2013; Lei and Xue 2009; Shi et al. 2007; Siggins et al. 2010; Xue and Lei 2006; Xue and Ohsumi 2004), but also on the hydrodynamic behaviour of the two phase solution (Akbarabadi and Piri 2013; Krevor et al. 2012; Levine et al. 2013; Perrin and Benson 2010) to analyse $\mathrm{CO}_{2}$ spreading efficiency. However, few experimental works combining simultaneous analysis of different properties have been performed, such as linking geophysical properties with physico-chemical reactions (Canal et al. 2013; Hangx et al. 2010), hydrodynamic behaviour (Alemu et al. 2013; Berg et al. 2013; Nakatsuka et al. 2010), or mechanical responses associated with water- $\mathrm{CO}_{2}$-rock interactions (Hangx et al. 2013; Hangx et al. 2010; Vialle and Vanorio 2011; Zemke et al. 2010).

$\mathrm{CO}_{2}$ storage simulations in the laboratory are commonly addressed by pore fluid substitution tests under real reservoir conditions (i.e., temperature, and confining and pore pressures) with the aid of special high pressure, high temperature rigs. The experimental rigs combine diverse instrumentation to monitor pore fluid evolution with other systems to measure changes in the original properties of the rock (e.g., permeability or porosity). The most usual case of study is an originally brine saturated rock sample that is subjected to $\mathrm{CO}_{2}$ or $\mathrm{CO}_{2}$-brine mixture flow. This sort of flooding test can be carried out using either steady or unsteady state flow 
techniques (Müller 2011). X-ray computed tomography_(CT) is the preferred tool to accurately measure $\mathrm{CO}_{2}$ partial saturations (Berg et al. 2013; Krevor et al. 2012; Nakagawa et al. 2013; Oh et al. 2013; Perrin and Benson 2010), which is crucial to fit relative permeability curves or calibrate poroelastic numerical models (Mavko et al. 2009). However, electrical resistivity tomography (ERT) appears as an alternative method to calculate $\mathrm{CO}_{2}$-brine saturations (Alemu et al. 2013; Wang et al. 2009) because of the great electrical conductivity difference between $\mathrm{CO}_{2}$ and brine. In contrast to $\mathrm{CT}$, electrical resistivity has been successfully applied in situ at real $\mathrm{CO}_{2}$ sites (Carrigan et al. 2013).

To address changes in reservoirs based on the THMC concept, we have designed a unique multidisciplinary plan which combines experimental testing of rock samples exposed to $\mathrm{CO}_{2}$ injection under realistic environmental and geological conditions with state-of-the-art data analysis and interpretation. The experimental procedure is based on coupling geophysical and hydromechanical monitoring, controlling real P-T (pressure-temperature) reservoir conditions and fluid composition. Here, we present a demonstration of our novel experimental rig by simulating variable pore pressure conditions in shallow, low permeable reservoirs (e.g., the sort of Svalbard pilot-scale CCS project (Farokhpoor et al. 2014; Senger et al. 2015ł) at target depths of c. $900 \mathrm{~m}$ and a porosity of $25.9 \%$. Accordingly, we conduct a drainage flooding test through synthetic brine saturated sandstone changing the brine- $\mathrm{CO}_{2}$ fraction of pore fluid while simultaneously evaluating ultrasonic wave velocity and attenuation, electrical resistivity, axial strains and relative permeability, under variable injection induced pore pressure scenarios. 


\section{Materials and Methods}

\subsection{Sample core plug \\ Synthetic sandstones represent ideal reservoir samples that are unaffected by} micro-structural damage associated with the unloading process that any core suffers when extracted from deep geological formations (Lei and Xue 2009). Hence, we used in this study a $5 \mathrm{~cm}$ diameter, $2 \mathrm{~cm}$ length, brine-saturated synthetic silicacemented sandstone. The sample was made according to the manufacturing process presented by Tillotson et al. (2012). The mineralogy estimated via X-ray diffraction for this process is $>90 \%$ silica (Tillotson et al. 2012). The porosity was determined by helium injection porosimetry resulting in 0.259 , which converted into a pore volume of $\sim 10 \mathrm{~cm}^{3}$.

\subsection{Experimental rig}

Figure 1 shows a schematic diagram of our experimental rig. It is an upgraded version for two fluids injection of the rig presented by Falcon-Suarez et al. (2014). The rig is designed around a triaxial cell core holder that allows rock samples to be subjected to confining pressures up to $69 \mathrm{MPa}$. The confining fluid (mineral oil) is delivered from a dual pumping controller Teledyne ISCO model EX100D, configured in a non-coupled mode to independently set axial and radial target confining stresses. Inside the triaxial cell, the rubber sleeve that isolates the core plug from the confining fluid is equipped with 16 electrodes for electrical resistivity tomography measurements (ERT, see North et al. (2013)); strain gauges (350 Ohm) are also added on the sleeve-wall to measure axial and lateral strains during the test. Both signals are extracted via feedthrough connectors. The sample is indirectly in contact with the ultrasonic pulse-echo instrumentation (two buffer rods in between, see below) for measuring the ultrasonic velocity and the ultrasonic attenuation (Best et 
al. 2007). As explained on the inner cell zoom drawing of Figure 1, the core plug is isolated from the rest of the rig and the ultrasonic transducer by two acrylic buffer roads. These buffer rods have well defined acoustic impedance and low energy loss, providing a reliable delay path to enable the identification of top/base sample reflections for calculating wave velocities and attenuations. The buffer rods implement pathways (inlet and outlet ports) to conduct the pore fluid through the sample. The surfaces of the buffer rods in contact with the sample are specially designed with circumferential fluid flow pathways to facilitate the fluid spreading upstream and the collection downstream.

Likewise the confining pressure, pore fluids are transferred using a dual pumping controller Teledyne ISCO model EX100D configured in an independent mode. An additional single controller Teledyne ISCO model ED100 is used to provide back pressure to accurately control the pore pressure downstream of the sample. The pore fluids are indirectly supplied via fluid transfer vessels (FTVs). The aim of these vessels is twofold: firstly, to prevent potential damage to the controller from the high corrosiveness of brine and $\mathrm{CO}_{2}$; and secondly, to heat the fluids to target conditions by direct immersion of the FTVs in a thermal bath (up to $100{ }^{\circ} \mathrm{C}$ ). As a result, three vessels are connected to three pumping controllers: two for transferring brine and $\mathrm{CO}_{2}$ into the sample, and one for receiving the resulting fluid while setting the pore pressure constant. To further quantify the pore pressure, two piezo-resistive pressure transmitters (Keller model PA-33X) are inserted up- and downstream in the hydraulic system to accurately measure pressure, but also the temperature changes during the test. The remaining part of the experimental rig outside the thermal bath is enclosed in a commercial greenhouse cover system dotted with heat fans and automatic controllers to keep constant the temperature of 
the rig. Additionally, the triaxial cell is also wrapped with an electrical rope heater connected to a PID (proportional/integral/derivative) controller (maximum temperature $150^{\circ} \mathrm{C}$; accuracy $\pm 0.5^{\circ} \mathrm{C}$ ) which set the target temperature in the vessel according to the information received from an inner-vessel thermocouple.

\title{
2.3 Test methodology
}

The experiment was a steady state drainage test (Müller 2011), in which an electrical resistivity method was used to observe the fluid distribution in the porous medium. The sample was saturated first in degassed $35 \mathrm{~g} \mathrm{~L}^{-1} \mathrm{NaCl}$-brine via water imbibition in a vacuum vessel. The assumption of saturation was based on the fact that the porosity according to water-weight was less than $0.6 \%$ lower than the one obtained from helium porosimetry.

\begin{abstract}
Once inside the cell, the sample was hydrostatically confined $\left(\sigma_{c}\right)$ at $16.5 \mathrm{MPa}$ (simulating $~ 900 \mathrm{~m}$ depth "shallow" reservoir conditions) and the pore pressure $\left(P_{\rho}\right)$ set at $8.2 \mathrm{MPa}$ using the backpressure pumping controller downstream. The pore fluid was injected from the bottom end of the sample to remove remaining air bubbles from the pore space, at a constant flow rate. To avoid alterations of sample properties due to overloading while reaching the initial conditions of the test, the confining and pore pressures were simultaneously increased keeping the effective
\end{abstract} pressure $\left(P_{\text {eff }}=\sigma_{c^{-}} P_{p}\right)$ lower than the test-starting target conditions (i.e., $P_{\text {eff }}=8.3$ $\mathrm{MPa}$ ). The temperature was set at $35^{\circ} \mathrm{C}$ to be above the critical point of $\mathrm{CO}_{2}$ (i.e., $31^{\circ} \mathrm{C}, 7.39 \mathrm{MPa}$ ). After 4 days of compaction and settlement (geomechanical stabilisation), the sample was subjected to a $0.25 \mathrm{ml} \mathrm{min}^{-1}$ brine-flow, which is an accepted value for field flow rates (Berg et al. 2013), while setting the pressure downstream to $8.2 \mathrm{MPa}$. Thereafter, an unload/loading sequence of effective pressure was reproduced by increasing the pore pressure downstream $1.2 \mathrm{MPa}$ 
stepwise from $8.2 \mathrm{MPa}$ to $11.8 \mathrm{MPa}$ and back to $8.2 \mathrm{MPa}$, while keeping the confining pressure constant at $16.5 \mathrm{MPa}$. For each step, time was taken to allow a minimum of one pore volume (PV) to circulate through the sample while pore pressure upstream and strains were continuously recorded. Additionally, at the end of each step, electrical resistivity and ultrasonic measurements were collected.

After the first flooding sequence, the initial $100 \%$ brine solution was replaced by brine- $\mathrm{CO}_{2}$. The new solution injected into the sample was obtained by mixing variable volumetric flow rates of brine and $\mathrm{CO}_{2}$ (differential fractional flows) independently set by the corresponding controller. The resulting flow $(Q)$ was kept constant at $0.25 \mathrm{ml} \mathrm{min}{ }^{-1}$ for all the fractional brine: $\mathrm{CO}_{2}$ flows that were used (i.e., $Q$

Formatted: Font: Italic

Formatted: Font: Italic $\left.=Q_{w}+Q_{(\mathrm{CO} 2}\right)$. The methodology is similar to that proposed in previous water- $\mathrm{CO}_{2}$ flooding studies (Akbarabadi and Piri 2013; Krevor et al. 2012; Perrin and Benson 2010): both fluids meet at certain point in the high pressure hydraulic network, flowing together thereafter along $12 \mathrm{~m}$ length, $1.6 \mathrm{~mm}$-ID-pipe (which takes a time of $\sim 2 \mathrm{~h}$ at the experimental flow rate) before reaching the sample. The assumption of brine- $\mathrm{CO}_{2}$ equilibrium is based on the results shown by (El-Maghraby et al. 2012). They demonstrated that for a one litre vessel containing brine- $\mathrm{CO}_{2}$ at similar P-T conditions to those used in the present study $\left(\mathrm{CO}_{2}\right.$ at supercritical state), the time needed to achieve the equilibrium between both phases was approximately one hour. We assume this time should be enough to equilibrate the fluid in our pipereservoir system, since the cross section, and also the total volume displaced, are at least two orders of magnitude lower than those used by El-Maghraby et al. (2012).

This experimental procedure was repeated six times, varying $20 \%$ stepwise the fractional brine: $\mathrm{CO}_{2}$ flow up to $100 \% \mathrm{CO}_{2}$ (final stage). Between two consecutive unload/loading sequences, the existing pore fluid was replaced by the new solution. 
So, before starting the measurements, the new solution was forced to flow through the sample at the initial $P_{p}$ of the sequence (8.2 MPa) until the measured electrical resistivity stabilised (in all cases, no less than $4 \mathrm{PVs}$ ).

\subsection{Ultrasonic measurements}

Ultrasonic $\mathrm{P}$ - and S-wave velocities $\left(V_{p}\right.$ and $\left.V_{s}\right)$ and attenuations (inverse quality factors $Q_{p_{-}^{-1}}$ and $Q_{s_{-}}^{-1}$ ) were measured using the pulse-echo technique (McCann and Sothcott 1992), which provides useable frequencies between 300 $1000 \mathrm{kHz}$ with absolute accuracies of $\pm 0.3 \%$ for velocity and $\pm 0.1 \mathrm{~dB} \mathrm{~cm}^{-1}$ for attenuations (for $2.54 \mathrm{~cm}$ diameter single mode transducers); here we used dual P/S wave transducers which give accuracies of $\pm 0.3 \%$ for velocity and $\pm 0.2 \mathrm{~dB} \mathrm{~cm}^{-1}$ for attenuation (Best 1992). P- and S-wave velocities and attenuations were measured air dry, brine saturated, and for increasingly $\mathrm{CO}_{2}$ saturated brine solutions corresponding to the pore fluid composition imposed by each fractional brine: $\mathrm{CO}_{2}$ flow. For every single fluid composition, the monitoring parameters covered each unload/loading effective pressure step.

\subsection{Electrical resistivity, partial saturation and pore fluid}

Electrical resistivity was measured with a 16 electrodes, tetra-polar electrode configuration radially distributed in two rings around the plug, capable of assessing heterogeneity and anisotropy without previous information of sample properties (North et al. 2013). Under typical operating conditions the resistivity measurement error is $\sim 5 \%$ (at frequencies $1-500 \mathrm{~Hz}$ ) for samples in the electrical resistivity range 1-100 $\Omega \mathrm{m}$. Detailed information about system configuration and the data processing can be found in North et al. (2013) and North and Best (2014). The data acquisition was systematically performed immediately after each ultrasonic measurement,
Formatted: Font: Italic

\begin{tabular}{l} 
Formatted: Font: Italic \\
\hline Formatted: Font: Italic \\
Formatted: Font: Italic \\
Formatted: Font: Italic
\end{tabular}


obtaining comparable values between ultrasonic parameters and electrical resistivity. The raw data for every single acquisition resulted in a total of 208 measurements, from which an electrical resistivity average value and the inversion model were calculated. While tomography images from the inversion were used to visualise distribution patterns of pore fluid across the sample, the electrical resistivity average was used to compare results against other variables and also to determine the partial saturation of brine: $\mathrm{CO}_{2}$ in the sample.

The degree of saturation of brine $\left(S_{w}\right)$ is related to the bulk electrical resistivity $\left(E R_{b}\right)$ of a rock through the connectivity of the porous medium and the electrical resistivity of the pore fluid $\left(E R_{w}\right)$ according to Archie's law (Archie 1942):

$$
E R_{b}=\frac{E R_{w}}{\varphi^{m} S_{w}^{n}} a
$$

where $\varphi$ is the porosity, $a$ is a proportionality constant, $m$ is the cementation factor of the material and $n$ the saturation exponent. The latter three parameters are empirically adjusted or assumed for a particular type of rock. In our experiment, the initial stage is $100 \%$ brine saturation so that the initial bulk electrical resistivity $\left(E R_{0}\right)$ can be expressed as:

$$
E R_{0}=\frac{E R_{w}}{\varphi^{m}} a
$$

The experimental test is a two-phase solution system, hence the evolution of the brine or $\mathrm{CO} 2$ saturation (i.e., $S_{w}=1-S_{\mathrm{CO} 2}$ ) can be obtained dividing equation (1) by equation (2) (Carrigan et al. 2013; Nakatsuka et al. 2010):

$$
S_{w}=\left(\frac{E R_{0}}{E R_{b}}\right)^{1 / n}
$$


In our unload/loading sequence test $E R_{b}$ varies by the effect of compaction. So, we calculated $E R_{0}$ for each effective pressure of each brine-saturation stage, adopting the corresponding values thereafter to solve equation (3). Nonetheless, it is worth noting that this expression is only valid if $E R_{w}$ remain constant with time, which is the case of a chemically non-reactive scenario. Otherwise, $S_{w}-E R_{b}$ relations should be addressed using equation (1). In this regard, the pore fluid was sampled at the end of each fractional brine: $\mathrm{CO}_{2}$ flow stage, and $E R_{w}$ determined with a commercial conductivity metre (up to $19.99 \mathrm{mS} \mathrm{cm}^{-1}$ ). The results were surprisingly constant and close to the original brine $(0.189 \Omega \mathrm{m}): E R_{w}=0.191 \pm 0.009 \Omega \mathrm{m}$. Since no preferential trends were identified in the $E R_{w}$, we assumed the flooding test was chemically stable and adopted equation (3) to calculate the changes in the degree of saturation. The latter assumption is supported by the fact that no porosity changes were identified after the test.

\subsection{Absolute and relative permeability}

By changing the fractional brine: $\mathrm{CO}_{2}$ flow, we determined the relative permeability curves for both phases at the simulated reservoir conditions. We used the steady state relative permeability method of Müller (2011). As a first step, the sample permeability to brine was calculated for every $P_{\text {eff }}$ step at the initial brine: $\mathrm{CO}_{2}$ stage (100:0), using the well-known steady state flow method based on Darcy's law:

$$
k=\frac{\mu L Q}{\Delta P A}
$$

where $k$ is permeability, $Q$ the volumetric flow rate, $\Delta P$ the pressure drop across the sample, $A$ the cross sectional area, $L$ the length, and $\mu$ the dynamic viscosity of the fluid. We found that the equilibrium was achieved rapidly after a flow $\sim 0.1 \mathrm{PVs}$. This represents an advantage of our experimental setup related to the sample size $(\sim 2 \mathrm{~cm}$ 
length), respect to the rest of experimental configurations found in the relevant literature (for instance Akbarabadi et al. 2013 and Berg et al. 2013, use $\sim 15 \mathrm{~cm}$ length samples; Krevor et al. 2012, Alemu et al. 2013, Kitamura et al. 2014, $\sim 10 \mathrm{~cm}$; Canal et al. 2013 and El-Maghraby and Blunt 2013, 7.5 cm length; Chen et al. 2013, $7 \mathrm{~cm}$ length; and Chang et al. 2013, $\sim 5 \mathrm{~cm}$ length samples). Despite this, the minimum volume circulated during every step of the test was $1 \mathrm{PV}$.

Assuming an homogenous contribution of the whole cross sectional area to the flow through the entire core, the above expression can be modified for our two-phase brine- $\mathrm{CO}_{2}$ system in which the relative permeability of each phase $\left(k_{r, i}\right)$ is a function of the partial contributions to the total saturation (Krevor et al. 2012; Levine et al. 2013):

$$
k_{r, i}\left(S_{i}\right)=\frac{\mu_{i} L Q_{i}}{\Delta P A k_{a b s}}
$$

Note in the above expression that subscript $i$ refers to each phase. Since permeability clearly depends on the effective pressure (Nguyen et al. 2013), in the present work we used the maximum permeability measured during the first effective pressure sequence as the absolute permeability (i.e., $k_{a b s}=1.01 \mathrm{mD}$ ), in order to compare the magnitude of these changes. For permeability calculations, $\mathrm{CO}_{2}$ viscosity was determined according to Heidaryan et al. (2011) while brine viscosity was taken from Mavko et al. (2009).

Relative permeability curves with the Brooks-Corey model (Brooks and Corey 1964) for a brine- $\mathrm{CO}_{2}$ two phase system $\left(k_{r, w}\right.$ and $\left.k_{r, \mathrm{CO} 2}\right)$ and the fractional flow curve $\left(f_{\mathrm{CO} 2}\right)$ were performed as presented in Krevor et al. (2012):

$$
k_{r, w}=\left(S_{w}^{*}\right)^{N_{w}}
$$


where $N_{w}$ and $N_{\mathrm{CO} 2}$ are the Corey fitting-components for brine and $\mathrm{CO}_{2}$. In absence of data of irreducible water saturation $\left(S_{w r}\right)$, this parameter was considered an additional fitting parameter in the modelling.

\subsection{Strains}

Sample deformation was monitored from electrical strain gauges added to the wall of the rubber sleeve within the triaxial vessel, and additionally from the axial piston displacement proportional to the confining fluid injected from the servocontroller volumetric pump (Figure 1). Radial strain gauges were likewise added on the sleeve, but unfortunately the signal recorded was inaccurate due to the high compressibility of the thick rubber sleeve. Before and after the test, the results were first calibrated with a standard ( $5 \mathrm{~cm}$ diameter, $2 \mathrm{~cm}$ height aluminium sample). Then, a more recent modification of our triaxial cell allowed us to repeat an additional post-experiment calibration by directly adding strain gauges on the wall-side of the sample (water-saturated), covering the complete sequence of $P_{\text {eff. }}$ In Figure 2 we show the correlation between the deformation recorded by the gauges added on the sample $\left(G_{s a}\right)$ and those added on the sleeve $\left(G_{s l}\right)$.

During the flooding test, axial strains were measured with a sampling frequency of $0.08 \mathrm{~Hz}$ during brine: $\mathrm{CO}_{2}$ stages, covering the whole range of $P_{\text {eff }}$ and compositional steps. Then, only axial strains $\left(\varepsilon_{a x}\right)$ were considered and processed 


$$
\begin{aligned}
& \text { (the correction factor of Figure } 2 \text { was applied) in terms of relative longitudinal } \\
& \text { deformation according to equation (10): } \\
& \qquad \varepsilon_{a x}=\frac{\left(L_{0}-L\right)}{L_{0}} \cdot 100
\end{aligned}
$$

where $L_{0}$ and $L$ are the original and measured sample length, respectively. In the absence of radial strains, relative changes of porosity during the test were neglected.

\section{Experimental results}

The effective experiment extended $\sim 50$ hours. During this period, $67 \mathrm{PVs}$ at different brine: $\mathrm{CO} 2$ fractions circulated through the sample. Figure 3 shows the raw data obtained during this drainage test. The evolution of $\mathrm{P}$ - and S-wave velocities and their corresponding attenuations (frequency of $600 \mathrm{kHz}$ obtained from Fourier analysis of broad band signals), axial strain, relative permeability of each fluid phase and the electrical resistivity of the rock sample is plotted together for each of the six brine:CO2 unload/loading effective pressure sequences. For all of these measured parameters, Figure 3 shows that pore fluid effects are greater than effective pressure effects since transitions between sequences lead to more significant changes than those observed within a single sequence.

During the transition stages between two consecutive brine/CO2 episodes (indicated by grey vertical bands), both electrical resistivity and ultrasonic wave velocities were computed for every $1 \mathrm{PV}$ flushed through the sample. Although these data are not presented in this study, they were used to select the starting point of a new fluid stage upon data stabilisation. Even though this stabilisation occurred very quickly in some cases, we imposed a minimum flow of $4 \mathrm{PVs}$ before concluding the transition. This would be enough to reach an homogeneous fluid distribution in a 2 
cm length core sample, based on the results presented by (Oh et al. 2013) for a similar flooding test.

\subsection{Geophysical signatures}

Figure 3 shows $\mathrm{P}$-wave velocity $\left(V_{p}\right)$ gradually decreases with the $\mathrm{CO} 2$ saturation, by $\sim 7 \%$ at the end of the test. The highest drop ( $\sim \%)$ rapidly occurs after the first fluid change (brine:CO2 $=80: 20$ ), which agrees with the data reported by other authors (Alemu et al. 2013; Kitamura et al. 2014; Lei and Xue 2009; Shi et al. 2007; Xue and Ohsumi 2004). At higher CO2 contents, $V_{p}$ becomes less affected by fluid changes, coinciding with the results presented by (Alemu et al. 2013). The same effect can be seen for the S-wave velocity $\left(V_{s}\right)$, but after the first drop ( 4\%) the velocity becomes steady and mechanical variations become more significant. Pand S-wave attenuations (expressed by the inverse quality factors $Q_{p}{ }^{-1}$ and $Q_{s}{ }^{-1}$, respectively) show the opposite behaviour: $Q_{p}^{-1}$ increases with $\mathrm{CO} 2$ content (up to $\sim 55 \%$ ) evolving inversely comparing to $V_{p} ; Q_{s}{ }^{-1}$ decreases ( 25\%) with an inverse trend compared to $V_{s}$ caused by $P_{\text {eff }}$ unload/loading variations. Hence, according to the results, $V_{s}$ and $Q_{s}{ }^{-1}$ are better geomechanical indicators, while $V_{p}$ and $Q_{p}{ }^{-1}$ can provide useful information about pore fluid compositional changes.

The electrical resistivity $(E R)$ increases from $\sim 12 \Omega \mathrm{m}$ for pure brine to $\sim 45 \Omega \mathrm{m}$ during the last stage, where the highest $\mathrm{CO} 2$ saturation was achieved. While Figure 3 shows average resistivities, Figure 4 shows 3D electrical resistivity tomography images of the sample, corresponding to the minimum $P_{\text {eff }}$ step (i.e., $4.7 \mathrm{MPa}$ ) of each brine:CO2 stage. We only show one $P_{\text {eff }}$ step per brine:CO2 stage because changes between steps within a single stage are visually negligible. The stacked images correspond to sections at different heights through the sample, centred on the one in 
the middle. The radial distribution of electrical resistivity can be seen to become increasingly heterogeneous with increasing $\mathrm{CO} 2$ saturation.

Joint interpretation of acoustic and electrical properties is a fundamental step towards identifying and understanding reservoir changes and improving prediction models (Han et al. 2011; Han et al. 2015). We compare the ultrasonic wave velocities and electrical resistivity data of our drainage test in Figure $5 . V_{p}$ decreases with $E R$, which is in line with reported observations (Wang et al. 2009), while $V_{s}$ initially drops but then stabilizes. This is clearly showing the differential repercussion the fluid has on $V_{p}$. Plotting velocities versus electrical resistivity smooths the effect of the effective pressure on the data to better assess changes in the fluid composition, which is intensified through the $V_{p} V_{s}$ ratio (Figure 6). Likewise, the variations of the $\mathrm{P}$ - and $\mathrm{S}$-wave attenuations with the electrical resistivity are shown in Figure 7 and Figure 8, respectively. $Q_{p}^{-1}$ increases with the electrical resistivity, the opposite to $Q_{s}^{-1}$, making the $Q_{s} / Q_{p}$ ratio less diagnostic than $V_{p} V_{s}$ ratio for interpreting pore fluid changes. Nevertheless, this ratio provides useful information regarding the conversion of low resistivity values into brine/CO2 saturation because $Q_{s} / Q_{p}$ greater than unity means $S_{w}<0.9$ (Amalokwu et al. 2014; Murphy 1982), which occurs at resistivity values above $18 \Omega \mathrm{m}$.

\subsection{Sample deformation}

In Figure 3, the axial strain evolves within each effective pressure sequence as expected, i.e., recovering initial deformation during unloading to be newly gained while loading, oscillating less than $0.04 \%$ for every single sequence. The deformation carries hysteresis, in so far as after the loading ramp the final value is slightly higher than the original one for a single sequence. From the stage brine:CO2 60:40 onwards, the hysteresis effect is stronger, which is also reflected in the $V_{p}$ 
values. Nonetheless, the sample behaves quasi-elastically for a single sequence of effective pressure with a slight degree of cumulative damage, but reaching $\sim 0.06 \%$ of axial deformation after flow times of $60 \mathrm{PVs}$. The data agree reasonably well with the values reported by Xue and Ohsumi (2004) and Lei and Xue (2009) for similar experimental conditions, and Hangx et al. (2013) who showed strains approximately one order of magnitude higher, but from poorly consolidated carbonate- and quartzcemented samples.

\subsection{Relative permeability}

The relative permeability of both phases naturally increases with their respective partial saturations. Permeability and axial strain show opposite trends for a single brine:CO2 stage, indicating that the connectivity of the pores varies with effective pressure, with the exception of the last stage of brine:CO2 as mentioned above. The variation of pore connectivity is also reflected in the electrical resistivity of the rock for a single unload/loading effective pressure sequence; however, this parameter is primarily dependent on the electrical resistivity of the pore fluid, so that mechanical effects are very small compared to fluid changes. Nevertheless, to minimise the mechanical effect and emphasise the fluid dynamics, the permeability measured at each $P_{\text {eff }}$ step during the initial pure brine flooding stage was used as the particular absolute permeability for the same steps at the subsequent brine:CO2 stages. Resistivity measurements carry an error $\sim 5 \%$. This has only a small impact on the calculation of the degree of saturation if brine saturation is high, but increases with $\mathrm{CO} 2$ saturation up to $5 \%$.

Brine saturation (i.e., $S_{w}=1-S_{C O 2}$ ) was computed from the average value of electrical resistivity, using equation (3). Accordingly, the maximum $\mathrm{CO} 2$ saturation achieved during the experiment was $S_{\mathrm{CO}_{2}} \sim 0.5$, which is likewise indicative of the 
brine that $\mathrm{CO} 2$ is able to displace under the simulated test conditions. In other words, this value indicated the maximum $\mathrm{CO} 2$ storage capacity of an idealised reservoir (Kitamura et al. 2014). The capillary number $N_{c}=v \mu / \sigma$ (where $v$ is Darcy velocity in $\mathrm{m} \mathrm{s}^{-1}, \mu$ viscosity in $\mathrm{Pa} \mathrm{s}$, and $\sigma$ the interfacial tension in $\mathrm{N} \mathrm{m}^{-1}$ ), was calculated to obtain the magnitude of the relation between viscous and pore scale capillary forces. In our case $N_{c} \sim 10^{-10}$, but it has been proposed that $N_{c}$ only affects relative permeability estimations if $>10^{-6}$ (Akbarabadi and Piri 2013; Krevor et al. 2012). Figure 9 shows the relative permeability curve fits to our experimental data. Since electrical resistivity slightly varies as a result of $P_{\text {eff }}$ changes, we address the study of the relative permeability from a global plot without considering the differential mechanical effects. The best-fit Corey exponents for brine and $\mathrm{CO} 2$ were found to be $N_{w}=7$ and $N_{\mathrm{CO} 2}=0.5$, and $S_{w r}=0.15$, while the maximum $k_{r, \mathrm{CO} 2}=0.05$ (at $S_{\mathrm{CO} 2}=0.5$. The value obtained for $k_{r, \mathrm{CO} 2}$ might be underestimated because, according to (Krevor et al. 2012), when 100\% CO2 is injected the steady state flow method stabilises and the observed pressure gradient is related to the capillary pressure rather than to the permeability. Pini et al. (2012) presented an experimental method based on changes of flow rates to obtain the permeability through the slope of the flow rate versus the pressure gradient to calculate the permeability at this point. We did not apply it during this test, but it will be carried out in future experiments.

Furthermore, the inner plot in Figure 9 shows the fractional flow to $\mathrm{CO} 2$ saturation. The experimental data points fit well the theoretical estimation. Nevertheless, for low fractional flow stages the observed $S_{\mathrm{CO} 2}$ is lower than predicted. This indicates the low influence of $\mathrm{CO} 2$ on the resistivity at such high brine saturations, an issue that will be discussed in the following section. In this regard, we 
have included one unique cross error in Figure 9 to facilitate the visualization: horizontally, we show the error associated with the electrical resistivity transferred to the calculated degree of saturation (also both horizontal and vertical error bars in the inner plot); vertically, the error regarding the influence of the neglected effect of dissolved $\mathrm{CO} 2$ in the relative permeability. The latter error is calculated based on the data presented by Berg et al. (2013) for very similar experimental conditions to the present work. According to that work, the solubility of $\mathrm{CO} 2$ in water is about $1.79 \mathrm{~mol} \%$, i.e., up to 9 vol\% dissolved $\mathrm{CO} 2$ into the aqueous phase. So, our $\mathrm{CO} 2$ flow rate would be likewise overestimated and therefore the relative permeability.

\section{Discussion}

\subsection{Comparison to predictions by Gassmann's model}

The theoretical modelling of changes in our ultrasonic data as a result of fluid substitutions was primarily addressed using the Gassmann equation (Gassmann, 1951). Based on the concept of poroelasticity, Gassmann's model predicts variations in elastic wave velocities $\mathrm{Vp}$ and $\mathrm{Vs}$ in saturated porous media as follow:

$$
\begin{aligned}
& V_{p}=\left(\frac{K_{b}+\frac{4}{3} G_{b}}{\rho_{b}}\right)^{1 / 2} \\
& K_{b}=K_{d}+\frac{\left(1-K_{d} / K_{m}\right)^{2}}{\varphi / K_{f}+(1-\varphi) / K_{m}-K_{d} / K_{m}^{2}}
\end{aligned}
$$

where $K_{b}$ and $G_{b}$ the bulk modulus and the shear modulus of the rock of bulk density $\rho_{b}$ and porosity $\varphi$. As shown in equation (12) $K_{b}$ is related to the dry rock frame modulus, solid mineral bulk modulus and the fluid bulk modulus (subscripts $d, m$ and $f$, respectively). As $G_{b}$ is unaffected by the fluid saturation, then $G_{b}=G_{d}=\rho_{b} V_{s} \cdot \ln$ 
our two phase system, the bulk density is expressed as follows to address the effect of each fluid on the total $\rho_{b}$ value:

$$
\begin{aligned}
& \rho_{b}=(1-\varphi) \rho_{m}+\varphi \rho_{f} \\
& \rho_{f}=\rho_{w}\left(1-S_{\mathrm{CO}_{2}}\right)+\rho_{\mathrm{CO}_{2}} S_{\mathrm{CO}_{2}}
\end{aligned}
$$

Note that bulk modulus subscript $w$ and $\mathrm{CO} 2$ refers to brine and $\mathrm{CO} 2$ (i.e., $S_{w_{-}}=$ 1-S $\left.S_{(\mathrm{CO}}\right)$. Likewise, as described in Kitamura et al. (2014) or Chen et al. (2013) and based on Woods' fluid mixing law, the bulk modulus of the brine- $\mathrm{CO}_{2}$ solution is calculated as follow:

$$
K_{f}^{-1}=\left(\frac{K_{\mathrm{CO}_{2}}}{S_{\mathrm{CO}_{2}}}\right)^{-1}+\left(\frac{K_{w}}{S_{w}}\right)^{-1}
$$

In the equation above, the modulus of each component was calculated from the relations presented by Batzle and Wang (1992), for each of the P-T experimental conditions. See details of calculation parameters on Table 1.

Figure 10 and Figure 11 show experimental data and Gassmann estimates for $\mathrm{P}$ - and S-wave velocity. Initial experimental velocities obtained during pure brine flow (i.e., $100 \%$ brine saturation) are higher than the Gassmann predictions, an effect that can be attributed to additional dispersion mechanisms due wave-induced local fluid flow mechanisms not considered in Gassmann's model (Winkler 1985; Chapman et al. 2002; Sarout 2012). Thereafter, Gassmann predictions fits better to $V_{p}$ data at high and very low $\mathrm{CO}_{2}$ saturations; between $10-20 \% \mathrm{CO}_{2}$ saturation, the model underestimates $V_{p}$ by $\sim 3.5 \%$ on average. While no clear $V_{p}-P_{\text {eff }}$ relations are observed between experimental data and predictions, in the case of $V_{s}$, the same trend is observed for every single effective pressure, although Gassmann's model 
overestimates $V_{s}$ by $\sim 2 \%$ in all cases. Since $V_{s}$ is relatively unaffected by the fluid, it is a good indicator of the geomechanical state of the rock, although we observe $V_{s}$ drops $6 \%$ between brine saturated and $20 \% \mathrm{CO}_{2}$ saturation, possibly related to local flow fluid mechanisms which is corroborated by $V_{p}$ data (e.g., Winkler and Nur 1982). Nonetheless, $V_{p}$ depends on the bulk modulus of the rock, and also the fluid bulk modulus. Hence, the dispersion of the data may suggest non-homogeneous distribution of the fluid in the pores of the rock sample.

\subsection{Comparison to predictions by White and Dutta-Ode' model}

To investigate the effect of sub-core scale heterogeneities on the fluid distribution pattern (patchy partial saturation), we used the model of White and Dutta-Odé (see Mavko et al. (2009)). The model is based on the assumption that in a partially saturated porous medium, the pore space is occupied by a single fluid which hosts spherical regions of a secondary fluid with contrasting bulk compressibility, i.e., in the present case brine hosting $\mathrm{CO}_{2}$. The idealised patchy spheres (each) have a radius denoted $b$ and $a$ for brine and $\mathrm{CO}_{2}$ spheres respectively, giving $S_{\mathrm{CO} 2}=(a / b)^{3}$. Furthermore, to analyse the two fluid saturation states it is also necessary to introduce the critical diffusion length parameter $L_{c}=\left(k K_{w} / \lambda \mu\right)^{1 / 2}$, where $k$ is the permeability, $\lambda$ is the ultrasonic frequency, and $K_{w}$ and $\mu$ the fluid bulk modulus and viscosity of the brine, respectively. $L_{c}$ is an indicator of whether the two phases in the porous medium are well distributed $\left(L_{c} \sim 0.01 \mathrm{~cm}\right.$ at our experimental conditions). That is, homogenous saturation exists if the fluids are mixed at a scale length $<L_{c}$ and a heterogeneous (or patchy) saturation if $>L_{c}$.

The effect of fluid modulus reduction on the overall rock-fluid bulk modulus during increasing $\mathrm{CO}_{2}$ saturation is analysed in Figure $12 \mathrm{a}-\mathrm{d}$, for each of the four effective pressures conditions. The model with $a=0.01 \mathrm{~cm}$ was found to yield results 
consistent with the experimental bulk modulus, which means that $b$ varies between $0.3-0.07 \mathrm{~cm}$ (decreasing with the $\mathrm{CO}_{2}$ saturation), and hence $L_{c} \ll<$ patch size. At this point, it is worth mentioning that the selected frequency $(600 \mathrm{kHz})$ lies between the cut-off frequencies between which the White and Dutta-Odé model is valid (see Lei and Xue (2009) for details): i) $b$ is at least 10 times lower than either the P- or Swave length ( 5 and $3 \mathrm{~mm}$, respectively); and ii) the so called transition frequency (upper limit), the frequency up to which Darcy flow is justified, varies in our case between $900-1200 \mathrm{kHz}$.

In this respect, the results can be linked to the heterogeneities observed from electrical resistivity tomography. Likely, these are associated with higher capillary pressure regions (predominantly larger than the diffusion length at the experimental conditions, but small enough to affect the relative permeability, i.e., $N_{c} \sim 10^{-10}$ ) preferentially occupied by the original brine solution (Shi et al. 2007; Xue and Lei 2006); while $\mathrm{CO}_{2}$ (of lower density and higher compressibility) would replace brine from higher pore size regions. Furthermore, a closer view of Figure $12 a-c$ reveals additional details about pore fluid heterogeneous distribution. Notice how the data related to unloading (solid circles) are slightly closer to patchy saturation than those of loading (open circles). This could be indicating a slight tendency to homogeneous saturation during loading, maybe related to fluid movements between pores by squeezing.

The P-wave attenuation (inverse quality factor) observations shown in Figure $13 a-d$ are much larger than the model predicted values, which agrees with results previously reported (Amalokwu et al. 2014; Nakagawa et al. 2013). Figure 13a - d show $Q_{p}^{-1}$ experimental data with White and Dutta-Odé predictions for the whole saturation range. The model predicts a rapid increase in P-wave attenuation with a 
peak at $\sim 25 \%$ of $\mathrm{CO}_{2}$, followed by a gradual decrease towards higher $\mathrm{CO}_{2}$ saturation. Our data lie far above the predicted values both under unloading or loading, but follow an increasing trend from initial $\mathrm{CO}_{2}$ saturation states up to peak values at maximum experimental $\mathrm{CO}_{2}$ saturations; unlike the model predictions, there is no evidence for a drop off at higher $\mathrm{CO}_{2}$ saturations.

As expected, the replacement of the initial brine by brine- $\mathrm{CO}_{2}$ solution had a striking effect on both the ultrasonic wave velocity and attenuation. Although several damping mechanisms have been proposed to describe these phenomena (Müller et al. 2010; Lei and Xue 2009), the homogeneity of our synthetic sample, the low deformation observed during the test, and the invariable porosity and pore fluid electrical conductivity (i.e., no geochemical effects), suggest that viscous fluid flow mechanisms are the cause. Attenuation observations are especially important to explain changes above $20 \% \mathrm{CO}_{2}$ saturation, when $\mathrm{P}$-waves become less sensitive to fluid changes. The White and Dutta-Odé model could explain in part the observed attenuations, at least the trend of one limb of the model curve, but the higher measured attenuations suggest the presence of other loss mechanisms, as yet unidentified. However, bulk modulus appears to be a good indicator of the rock-fluid state, even showing some sort of squeezing phenomenon related to loading, as previously mentioned, that could help to identify potential overpressure reservoir conditions in real $\mathrm{CO}_{2}$ storage sites.

\subsection{Ultrasonic data quality assessment}

Regarding the ultrasonic attenuation mechanisms mentioned above, it is worth showing the ultrasonic frequency spectra to check data quality, as in Figures $13 \mathrm{a}-\mathrm{d}$, and to confirm the valid frequency ranges for observation of fluid flow loss mechanisms. According to Best (1992), the ultrasonic pulse-echo system as 
configured in this work (using a dual P/S wave transducer of effective radius 0.89 $\mathrm{cm}$ ) gives usable $\mathrm{P}$-wave results above $580 \mathrm{kHz}$ for a rock $V_{p}$ of $4 \mathrm{~km} \mathrm{~s}^{-1}$ or lower, and above $330 \mathrm{kHz}$ for S-waves for a rock $V_{s}$ of $2.5 \mathrm{~km} \mathrm{~s}^{-1}$ or lower. Accuracies are \pm $0.3 \%$ for velocity and $\pm 0.2 \mathrm{~dB} \mathrm{~cm}^{-1}$ for attenuation coefficient (about $\pm 10 \%$ for $Q=$ 50; see Best et al. (1994)). The upper frequency limits for P- and S-waves are determined by signal to noise ratio, often caused by the onset of Rayleigh scattering as the wavelength approaches the size of any heterogeneities such as sand grains, or in this case, liquid/gas patches. In our case, this is no relevant since we used fine sand to make the synthetic sample, which means the grains $(<75 \mu \mathrm{m})$ were over ten times smaller than the wavelength.

In Figure $14 a, V_{p}$ decreases smoothly (although non-monotonically) with frequency by c. $0.25 \%$ between $500-800 \mathrm{kHz}$ for all saturations states, but $V_{s}$ increases up to about $700 \mathrm{kHz}$ (by c. $0.6 \%$ from $400-700 \mathrm{kHz}$ ) before dropping off at higher frequencies for all saturation states (Figure 14b). As the percentage change is small compared to the absolute velocities (but nevertheless significant relative to the measurement accuracy), we will not try to further interpret the underlying causes here. However, as noted above, the attenuation values in Figure $13 a-d$ suggest other attenuation mechanisms are present at $600 \mathrm{kHz}$ apart from the White-Dutta-Odé mechanism (at least, as modelled); they could be related to the negative $V_{p}$ dispersion seen in Figure $13 a-d$. However, $V_{s}$ shows "normal" positive dispersion (Figure 14b) as we would expect from squirt flow dispersion mechanisms; the high frequency drop-off is possibly due to poor signal-to-noise ratio.

\section{P-wave attenuation $Q_{p}^{-1}$ in Figure $14 c$ shows an almost linear increase with} frequency between about $500-800 \mathrm{kHz}$; we can ignore values below about $400 \mathrm{kHz}$ as they are probably affected by beam spreading/sidewall reflections. However, S- 
wave attenuation $Q_{s}^{-1}$ is variable in the useable bandwidth (Figure 14d), which is unexplained.

While providing the velocity and attenuation spectra may increase uncertainty in the ultrasonic observations, in fact these data provide a rich source of information on possible loss mechanisms which might be helpful for future interpretations. What is clear is that the ultrasonic velocity and attenuation results are consistent between saturation states, and hence provide confidence in the observed relative changes between saturation states at $600 \mathrm{kHz}$. The selected frequency of $600 \mathrm{kHz}$ in Figures 2, $4-7$ and $9-11$ is within the valid measurement range for the pulse-echo system as implemented here.

\subsection{Resistivity, saturation degree and relative permeability}

The central part of the sample is in all cases less resistive than the edges, suggesting preferential flow paths or a heterogeneous pore size distribution, but likely a combination of both. Chang et al. (2013) interpreted similar heterogeneities evident from transient dissolved $\mathrm{CO}_{2}$ concentrations during $\mathrm{CO}_{2}$ core flooding as areas where local non-equilibrium dissolution is occurring due to differential pore size distribution: smaller pores are occupied by water while larger pores, with lower capillary pressure, are dominated by $\mathrm{CO}_{2}$. However, since longitudinally the resistivity remains approximately constant, this idea reduces to very local areas. Similar longitudinal homogeneity of radial heterogeneities were observed by Perrin and Benson (2010) who suggested this indicates the absence of gravity or capillary end effects.

Transformation of electrical resistivity into degree of saturation is crucial to properly couple geophysical signatures and hydromechanical responses during our 
experiment. We observed anomalous low resistivity values related to the second brine: $\mathrm{CO}_{2}$ flow regime (i.e., 80:20 stage; Figure 3), which particularly affect the relative permeability curves and P-wave velocity prediction (Figure 9 and Figure 10). Likewise, the fractional flow represented in the inner plot of Figure 9 shows experimental $\mathrm{CO}_{2}$ saturations lower than predicted below $\mathrm{S}_{\mathrm{CO} 2}=0.2$. We interpret this lack of $\mathrm{CO}_{2}$ as a dissolution effect. According to Börner et al. (2013), $\mathrm{CO}_{2}$ would increase the electrical conductivity of the brine during dissolution, due to pressuredependent dissociation processes; however, high conductivity brines as the one we use in this work would mask the dissociation phenomena. Furthermore, instead of increasing, the dissolved $\mathrm{CO}_{2}$ might decrease the electrical resistivity due to either transformation into carbonic acid or mineral dissolution which would increase the concentration of ionic material especially relevant in the presence of carbonates (Dethlefsen et al. 2013). However, our sample is carbonates-free and it remained chemically stable according to the stability of the electrical conductivity of the pore fluid.

Hence, the electrical resistivity record is neglecting the $\mathrm{CO}_{2}$ dissolved fraction, and the total volume of $\mathrm{CO}_{2}$ in the pore space is likewise underestimated. This particularly affects the interpretation of the initial stages of the injection but is progressively attenuated with the $\mathrm{CO}_{2}$ saturation. So for instance, if we focus on the brine relative permeability in Figure 9, the estimations will improve with the displacement of the high brine saturation points to lower values. According to this observation, the electrical resistance method is useful for mapping the $\mathrm{CO}_{2}$ plume movement in the sub-surface, but it is limited to high concentrations, neglecting the dissolution trapping storage mechanism. 
Our results regarding the relative permeability coincide with observations by Perrin and Benson (2010) and later by Krevor et al. (2012); despite the absence of any observed capillary end effects or gravity forces, the maximum $S_{\mathrm{CO} 2}$ stays below 0.5. This threshold is likely to be imposed by the capillary forces of the porous medium, indicating the limit of the storage capacity of the sample. Further, because this study primarily aims at demonstrating the feasibility of the new experimental setup, we decided to remove the sample from the vessel after the $100 \% \mathrm{CO}_{2}$ injection stage had finished in order to measure the final brine saturation via wet-dry weight difference, to assess our results. The value obtained was $S_{w, f i n a l}=0.39$, which is $\sim 11 \%$ lower than the estimated value of 0.50 . This difference could be attributed to gravitational leakage during unloading and disassembly of the apparatus. For future works, we plan to estimate the residual trapping by injecting $100 \%$ brine after the last step, to obtain the residual $S_{\mathrm{CO} 2}$, i.e., the remaining $\mathrm{CO}_{2}$ immobilised in the pore space. This parameter is very important since it gives the remaining $\mathrm{CO}_{2}$ in the reservoir in a catastrophic reservoir-collapse scenario (Burnside and Naylor 2014).

\section{Conclusions}

We have conducted a drainage, steady state type, flooding test through a synthetic sandstone core plug under variable effective pressure, in order to simulate a realistic shallow, low permeable $\mathrm{CO}_{2}$ storage reservoir scenario. Ultrasonic $\mathrm{P}$ - and S-wave velocities and attenuations, electrical resistivity, axial strains and relative permeability were simultaneously monitored during the test.

On average, the injection of increasingly $\mathrm{CO}_{2}$ saturated brine resulted in $V_{p}$ and $V_{s}$ drops $\sim 7 \%$ and $\sim 4 \%$ respectively, while $Q_{p}{ }^{-1}$ increased $\sim 55 \%$ and $Q_{s}{ }^{-1}$ decreases $\sim 25 \%$. The Gassmann model predictions for $V_{p}$ are supported by the experimental data at low and very high $\mathrm{CO}_{2}$ saturations; $V_{s}$ is $\sim 2 \%$ overestimated although 
following the predicted trends. The bulk modulus is in good agreement with the White and Dutta-Ode' model. Despite $Q_{p}{ }^{-1}$ showing higher values than predicted, we can conclude that the observed velocity changes with $\mathrm{CO}_{2}$ saturation and energy loss are associated with heterogeneous fluid distribution within the sandstone pores medium rather than with internal discontinuities in the sandstone solid skeleton.

Fluid distribution patterns in the core were analysed through electrical resistivity tomography. The mean value was adopted to transform electrical resistivity into water saturation. Heterogeneities observed on tomography images at scales greater than the diffusion length for our experimental conditions corroborate the good agreement to the White and Dutta-Odé model. However, it is worth taking into consideration that during early stages of $\mathrm{CO}_{2}$ injection, the electrical resistivity is not reflecting the volume of $\mathrm{CO}_{2}$ dissolved in the brine, leading to an underestimation of the partial $\mathrm{CO}_{2}$ saturation.

The steady state method was applied successfully to determine relative permeability during the test. The electrical resistivity allowed us to relate relative permeability to partial saturation, and hence the application of theoretical curves. Additionally, relative permeability followed axial strain trends for every single unloading/loading sequence of effective pressure. Although clearly reflected on Pand S- wave velocities and their respective attenuations, or on the electrical resistivity, geomechanical effects played a secondary role in the present study due to the robust nature of the synthetic sandstone and the shallow conditions of the simulated reservoir. Instead, the experiment was dominated by changes in the pore fluid.

The novel experimental setup presented in this study has allowed us to successfully relate geophysical signatures to hydro-mechanical responses of a 
sandstone sample subjected to the injection of $\mathrm{CO}_{2}$. The increasing $\mathrm{CO}_{2}$ saturation stages and the oscillating effective pressure have simulated a wide range of scenarios that might occur during $\mathrm{CO}_{2}$ storage in a shallow, low permeable reservoir. We plan to develop future works covering real conditions of other reservoir types using a similar experimental protocol to facilitate the comparison of results between $\mathrm{CO}_{2}$ storage sites.

\section{Acknowledgments}

This work was carried out as part of the DiSECCS project with funding from the United Kingdom's Engineering and Physical Sciences Research Council (EPSRC) (grant EP/K035878/1) and the Natural Environment Research Council (NERC). We also thank Anna Lichtschlag (NOC) for help with pore fluid analysis, Jordi Delgado (University of La Coruña, Spain) for his valuable advices during the design stage of the experimental rig, and Anne-Kari Furre and Joel Sarout for their thorough review and valuable comments that have significantly improved the manuscript. 
References

Akbarabadi M. and Piri M. 2013. Relative permeability hysteresis and capillary trapping characteristics of supercritical $\mathrm{CO}_{2}$ /brine systems: An experimental study at reservoir conditions. Advances in Water Resources, 52(0), 190-206.

Alemu B.L., Aker E., Soldal M., Johnsen Ø. and Aagaard P. 2013. Effect of sub-core scale heterogeneities on acoustic and electrical properties of a reservoir rock: a $\mathrm{CO}_{2}$ flooding experiment of brine saturated sandstone in a computed tomography scanner. Geophysical Prospecting, 61(1), 235-250.

Amalokwu K., Best A.I., Sothcott J., Chapman M., Minshull T. and Li X.-Y. 2014. Water saturation effects on elastic wave attenuation in porous rocks with aligned fractures. Geophysical Journal International, 197(2), 943-947.

Archie G.E. 1942. The electrical resistivity log as an aid in determining some reservoir characteristics. Transactions of the American Institute of Mining, Metallurgical, and Petroleum Engineers, 146, 54-62.

Batzle M.L. and Wang Z. 1992. Seismic properties of pore fluids. Geophysics, 57(11), 1396-1408.

Berg S., Oedai S. and Ott H. 2013. Displacement and mass transfer between saturated and unsaturated $\mathrm{CO}_{2}$-brine systems in sandstone. International Journal of Greenhouse Gas Control, 12(0), 478-492.

Best A.I. 1992. The prediction of the reservoir properties of sedimentary rocks from seismic measurements, Ph.D. Thesis, University of Reading.

Best A.I., McCann C. and Sothcott J. 1994. The relationships between the velocities, attenuations and petrophysical properties of reservoir sedimentary rocks1. Geophysical Prospecting, 42(2), 151-178 
Best A.I., Sothcott J. and McCann C. 2007. A laboratory study of seismic velocity and attenuation anisotropy in near-surface sedimentary rocks. Geophysical Prospecting, 55(5), 609-625.

Börner J.H., Herdegen V., Repke J.-U. and Spitzer K. 2013. The impact of $\mathrm{CO}_{2}$ on the electrical properties of water bearing porous media - laboratory experiments with respect to carbon capture and storage. Geophysical Prospecting, 61, 446-460.

Brooks R.H. and Corey A.T. 1964. Hydraulic properties of porous media. Hydrology Paper 3. Colorado State University, Fort Collins, 27.

Burnside N.M. and Naylor M. 2014. Review and implications of relative permeability of $\mathrm{CO}_{2} /$ brine systems and residual trapping of $\mathrm{CO}_{2}$. International Journal of Greenhouse Gas Control, 23(0), 1-11.

Canal J., Delgado J., Falcón I., Yang Q., Juncosa R. and Barrientos V. 2013. Injection of $\mathrm{CO}_{2}$-Saturated Water through a Siliceous Sandstone Plug from the Hontomin Test Site (Spain): Experiment and Modeling. Environmental Science \& Technology, 47(1), 159-167.

Carrigan C.R., Yang X., LaBrecque D.J., Larsen D., Freeman D., Ramirez A.L., Daily W., Aines R., Newmark R., Friedmann J. and Hovorka, S. 2013. Electrical resistance tomographic monitoring of $\mathrm{CO}_{2}$ movement in deep geologic reservoirs. International Journal of Greenhouse Gas Control, 18(0), 401-408.

Chadwick A., Williams G., Delepine N., Clochard V., Labat K., Sturton S., Buddensiek M.-L., Dillen M., Nickel M., Lima A.L., Arts R., Neele F. and Rossi G. 2010. Quantitative analysis of time-lapse seismic monitoring data at the Sleipner $\mathrm{CO}_{2}$ storage operation. The Leading Edge, 29(2), 170-177. 
Chadwick R.A., Zweigel P., Gregersen U., Kirby G.A., Holloway S. and Johannessen P.N. 2004. Geological reservoir characterization of a $\mathrm{CO}_{2}$ storage site: The Utsira Sand, Sleipner, northern North Sea. Energy, 29(9-10), 1371-1381.

Chang C., Zhou Q., Xia L., Li X. and Yu Q. 2013. Dynamic displacement and non-equilibrium dissolution of supercritical $\mathrm{CO}_{2}$ in low-permeability sandstone: An experimental study. International Journal of Greenhouse Gas Control, 14(0), 1-14.

Chapman M., Zatsepin S.V. \& Crampin S. 2002. Derivation of a microstructural poroelastic model, Geophysical Journal International, 151, 427-451.

Chen H., Yang S., Huan K., Li F., Huang W., Zheng A. and Zhang X. 2013. Experimental Study on Monitoring $\mathrm{CO}_{2}$ Sequestration by Conjoint Analysis of the $\mathrm{P}$ Wave Velocity and Amplitude. Environmental Science \& Technology, 47(17), 1007110077.

Dethlefsen F., Köber R., Schäfer D., Hagrey S.A., Hornbruch G., Ebert M., Beyer M., Großmann J. and Dahmke A. 2013. Monitoring Approaches for Detecting and Evaluating $\mathrm{CO}_{2}$ and Formation Water Leakages into Near-surface Aquifers. Energy Procedia, 37, 4886-4893.

El-Maghraby R.M., Pentland C.H., Iglauer S. and Blunt M.J. 2012. A fast method to equilibrate carbon dioxide with brine at high pressure and elevated temperature including solubility measurements. The Journal of Supercritical Fluids, 62(0), 55-59.

Falcon-Suarez I., North L. and Best A., 2014. Experimental Rig to Improve the Geophysical and Geomechanical Understanding of $\mathrm{CO}_{2}$ Reservoirs. Energy Procedia, 59(0), 75-81. 
Farokhpoor R., Lindeberg E.G.B., Torsæter O., Mørk M.B. and Mørk A. 2014. Permeability and relative permeability measurements for $\mathrm{CO}_{2}$-brine system at reservoir conditions in low permeable sandstones in Svalbard. Greenhouse Gases: Science and Technology, 4(1), 36-52.

Gassmann F. 1951. Elastic waves through a packing of spheres. Geophysics, 16(4), 673-685.

Gaus I. 2010. Role and impact of $\mathrm{CO}_{2}$-rock interactions during $\mathrm{CO}_{2}$ storage in sedimentary rocks. International Journal of Greenhouse Gas Control, 4(1), 73-89.

Han T., Best A.I., MacGregor L.M., Sothcott J. and Minshull T.A. 2011. Joint elastic-electrical effective medium models of reservoir sandstones. Geophysical Prospecting, 59(4), 777-786.

Han T., Best A.I., Sothcott J., North L.J. and MacGregor L.M. 2015. Relationships among low frequency $(2 \mathrm{~Hz})$ electrical resistivity, porosity, clay content and permeability in reservoir sandstones. Journal of Applied Geophysics, 112(0), 279-289.

Hangx S., van der Linden A., Marcelis F. and Bauer A. 2013. The effect of $\mathrm{CO}_{2}$ on the mechanical properties of the Captain Sandstone: Geological storage of $\mathrm{CO}_{2}$ at the Goldeneye field (UK). International Journal of Greenhouse Gas Control, 19(0), 609-619.

Hangx S.J.T., Spiers C.J. and Peach C.J. 2010. Creep of simulated reservoir sands and coupled chemical-mechanical effects of $\mathrm{CO}_{2}$ injection. Journal of Geophysical Research: Solid Earth, 115(B9), B09205. 
Heidaryan E., Hatami T., Rahimi M. and Moghadasi J. 2011. Viscosity of pure carbon dioxide at supercritical region: Measurement and correlation approach. The Journal of Supercritical Fluids, 56(2), 144-151.

IPCC 2005. Special Report on Carbon Dioxide Capture and Storage: Prepared by Working Group III of the Intergovernmental Panel on Climate Change. Cambridge University Press, Cambridge and New York, 442 pp.

Kitamura K., Xue Z., Kogure T. and Nishizawa O. 2014. The potential of $V_{s}$ and $\mathrm{V}_{\mathrm{p}}-\mathrm{V}_{\mathrm{s}}$ relation for the monitoring of the change of $\mathrm{CO}_{2}$-saturation in porous sandstone. International Journal of Greenhouse Gas Control, 25(0), 54-61.

Krevor S.C.M., Pini R., Zuo L. and Benson S.M. 2012. Relative permeability and trapping of $\mathrm{CO}_{2}$ and water in sandstone rocks at reservoir conditions. Water Resources Research, 48(2), W02532.

Lei X. and Xue Z. 2009. Ultrasonic velocity and attenuation during $\mathrm{CO}_{2}$ injection into water-saturated porous sandstone: Measurements using difference seismic tomography. Physics of The Earth and Planetary Interiors, 176(3-4), 224-234.

Levine J.S., Goldberg D.S., Lackner K.S., Matter J.M., Supp M.G. and Ramakrishnan T.S. 2013. Relative Permeability Experiments of Carbon Dioxide Displacing Brine and Their Implications for Carbon Sequestration. Environmental Science \& Technology, 48(1), 811-818.

Mavko G., Mukerji T. and Dvorkin J. 2009. Rock Physics Handbook - Tools for Seismic Analysis in Porous Media. Cambridge University Press.

Müller N. 2011. Supercritical $\mathrm{CO}_{2}$-Brine Relative Permeability Experiments in Reservoir Rocks-Literature Review and Recommendations. Transport in Porous Media, 87(2), 367-383. 
Müller T.M., Gurevich B. and Lebedev M. 2010. Seismic wave attenuation and dispersion resulting from wave-induced flow in porous rocks - A review. Geophysics, 75(5), 75A147-75A164.

Murphy W.F. 1982. Effects of partial water saturation on attenuation in Massilon sandstone and Vycor porous glass. The Journal of the Acoustical Society of America, 71(6), 1458-1468.

Nakagawa S., Kneafsey T.J., Daley T.M., Freifeld B.M. and Rees E.V. 2013. Laboratory seismic monitoring of supercritical $\mathrm{CO}_{2}$ flooding in sandstone cores using the Split Hopkinson Resonant Bar technique with concurrent x-ray Computed Tomography imaging. Geophysical Prospecting, 61(2), 254-269.

Nakatsuka Y., Xue Z., Garcia H. and Matsuoka T. 2010. Experimental study on $\mathrm{CO}_{2}$ monitoring and quantification of stored $\mathrm{CO}_{2}$ in saline formations using resistivity measurements. International Journal of Greenhouse Gas Control, 4(2), 209-216.

Nguyen V.H., Gland N., Dautriat J., David C., Wassermann J. and Guélard J. 2013. Compaction, permeability evolution and stress path effects in unconsolidated sand and weakly consolidated sandstone. International Journal of Rock Mechanics and Mining Sciences, 67(0), 226 - 239.

North L., Best A.I., Sothcott J. and MacGregor L. 2013. Laboratory determination of the full electrical resistivity tensor of heterogeneous carbonate rocks at elevated pressures. Geophysical Prospecting, 61(2), 458-470.

North L.J. and Best A.I. 2014. Anomalous electrical resistivity anisotropy in clean reservoir sandstones. Geophysical Prospecting, 62(6), 1315-1326.

Oh J., Kim K.-Y., Han W.S., Kim T., Kim J.-C. and Park E. 2013. Experimental and numerical study on supercritical $\mathrm{CO}_{2} /$ brine transport in a fractured rock: 
Implications of mass transfer, capillary pressure and storage capacity. Advances in Water Resources, 62(C), 442-453.

Perrin J.-C. and Benson S. 2010. An Experimental Study on the Influence of Sub-Core Scale Heterogeneities on $\mathrm{CO}_{2}$ Distribution in Reservoir Rocks. Transport in Porous Media, 82(1), 93-109.

Pini R., Krevor S.C.M. and Benson S.M. 2012. Capillary pressure and heterogeneity for the $\mathrm{CO}_{2}$ /water system in sandstone rocks at reservoir conditions. Advances in Water Resources, 38(0), 48-59.

Rutqvist J. 2012. The geomechanics of $\mathrm{CO}_{2}$ storage in deep sedimentary formations. Geotechnical and Geological Engineering, 30(3), 525-551.

Sarout J. (2012). Impact of pore space topology on permeability, cut-off frequencies and validity of wave propagation theories. Geophysical Journal International, 189, 481-492.

Senger K., Tveranger J., Braathen A., Olaussen S., Ogata K. and Larsen L. 2015. $\mathrm{CO}_{2}$ storage resource estimates in unconventional reservoirs: insights from a pilot-sized storage site in Svalbard, Arctic Norway. Environmental Earth Sciences, 73(8), 3987-4009.

Shi J.-Q., Xue Z. and Durucan S. 2007. Seismic monitoring and modelling of supercritical $\mathrm{CO}_{2}$ injection into a water-saturated sandstone: Interpretation of P-wave velocity data. International Journal of Greenhouse Gas Control, 1(4), 473-480.

Siggins A.F., Lwin M. and Wisman P. 2010. Laboratory calibration of the seismo-acoustic response of $\mathrm{CO}_{2}$ saturated sandstones. International Journal of Greenhouse Gas Control, 4(6), 920-927. 
Tillotson P., Sothcott J., Best A.I., Chapman M. and Li X.-Y. 2012. Experimental verification of the fracture density and shear-wave splitting relationship using synthetic silica cemented sandstones with a controlled fracture geometry. Geophysical Prospecting, 60(3), 516-525.

Vialle S. and Vanorio T. 2011. Laboratory measurements of elastic properties of carbonate rocks during injection of reactive $\mathrm{CO}_{2}$-saturated water. Geophysical Research Letters, 38(1), L01302.

Wang Z., Gelius L.-J. and Kong F.-N. 2009. Simultaneous core sample measurements of elastic properties and resistivity at reservoir conditions employing a modified triaxial cell - a feasibility study. Geophysical Prospecting, 57(6), 10091026.

Winkler K. and Nur A. 1982. Seismic attenuation: effects of pore fluids and frictional sliding, Geophysics, 47, 1-15.

Winkler K.W. 1985. Dispersion analysis of velocity and attenuation in Berea sandstone. Journal of Geophysical Research: Solid Earth, 90(B8), 6793-6800.

Xue Z. and Lei X. 2006. Laboratory study of $\mathrm{CO}_{2}$ migration in water-saturated anisotropic sandstone, based on P-wave velocity imaging. Exploration Geophysics, 37(1), 10-18.

Xue Z. and Ohsumi T. 2004. Seismic wave monitoring of $\mathrm{CO}_{2}$ migration in water-saturated porous sandstone. Exploration Geophysics, 35(1), 25-32.

Zemke K., Liebscher A. and Wandrey M. 2010. Petrophysical analysis to investigate the effects of carbon dioxide storage in a subsurface saline aquifer at Ketzin, Germany $\left(\mathrm{CO}_{2} \mathrm{SINK}\right)$. International Journal of Greenhouse Gas Control, 4(6), 990-999. 
Table 1. Modelling parameters: physical properties of the synthetic sandstone and fluids, for the different effective pressures of the test (note that confining pressure is kept constant at $16.5 \mathrm{MPa}$ )

\begin{tabular}{|c|c|c|c|c|c|}
\hline \multicolumn{6}{|c|}{ Effective pressure (MPa) } \\
\hline Rock & 8.3 & 7.1 & 5.9 & 4.7 & Reference \\
\hline $\mathrm{K}_{\mathrm{m}}(\mathrm{GPa})$ & \multicolumn{4}{|c|}{36.32} & Estimated from XRD \\
\hline $\mathrm{K}_{\mathrm{d}}(\mathrm{GPa})$ & 12.56 & 12.45 & 12.40 & 12.43 & From dry $V_{p}$ and $V_{s}$ \\
\hline $\mathrm{G}_{\mathrm{d}}(\mathrm{GPa})$ & 11.02 & 10.97 & 10.87 & 10.72 & From $V_{s}$ \\
\hline$\rho_{\mathrm{s}}\left(\mathrm{kg} \mathrm{m}^{-3}\right)$ & \multicolumn{4}{|c|}{2592.8} & From $\rho_{d}$ \\
\hline$\phi$ & \multicolumn{3}{|c|}{0.259} & & Helium porosimetry \\
\hline $\mathrm{k}(\mathrm{mD})^{*}$ & 0.59 & 0.63 & 0.68 & 0.78 & From Darcy's law \\
\hline Fluid & 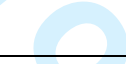 & & & & \\
\hline $\mathrm{K}_{\mathrm{CO} 2}(\mathrm{GPa})$ & 0.015 & 0.022 & 0.031 & 0.042 & Batzle and Wang (1992) \\
\hline$\rho_{\mathrm{CO} 2}\left(\mathrm{~kg} \mathrm{~m}^{-3}\right)$ & 542.8 & 686.5 & 732.5 & 762.9 & Batzle and Wang (1992) \\
\hline$\mu_{\mathrm{CO} 2}(\mathrm{~Pa} \mathrm{~s}) \cdot 10^{-5}$ & 3.11 & 4.15 & 4.99 & 5.68 & Batzle and Wang (1992) \\
\hline $\mathrm{K}_{\mathrm{w}}(\mathrm{GPa})$ & 2.503 & 2.509 & 2.516 & 2.523 & Batzle and Wang (1992) \\
\hline$\rho_{\mathrm{w}}\left(\mathrm{kg} \mathrm{m}^{-3}\right)$ & 1021.1 & 1021.6 & 1022.1 & 1022.6 & Batzle and Wang (1992) \\
\hline$\mu_{\mathrm{w}}(\mathrm{Pa} \mathrm{s})$ & \multicolumn{4}{|c|}{$7.4 \cdot 10^{-4}$} & Batzle and Wang (1992) \\
\hline
\end{tabular}

* Average of unload/loading values. No hysteresis effects were considered 
Figure 1. Experimental rig for $\mathrm{CO}_{2}$ storage simulations. Bottom right, a schematic inner cell view highlights the distribution of the different geophysical tools and strain gauges.

$$
241 \times 153 \mathrm{~mm}(150 \times 150 \mathrm{DPI})
$$




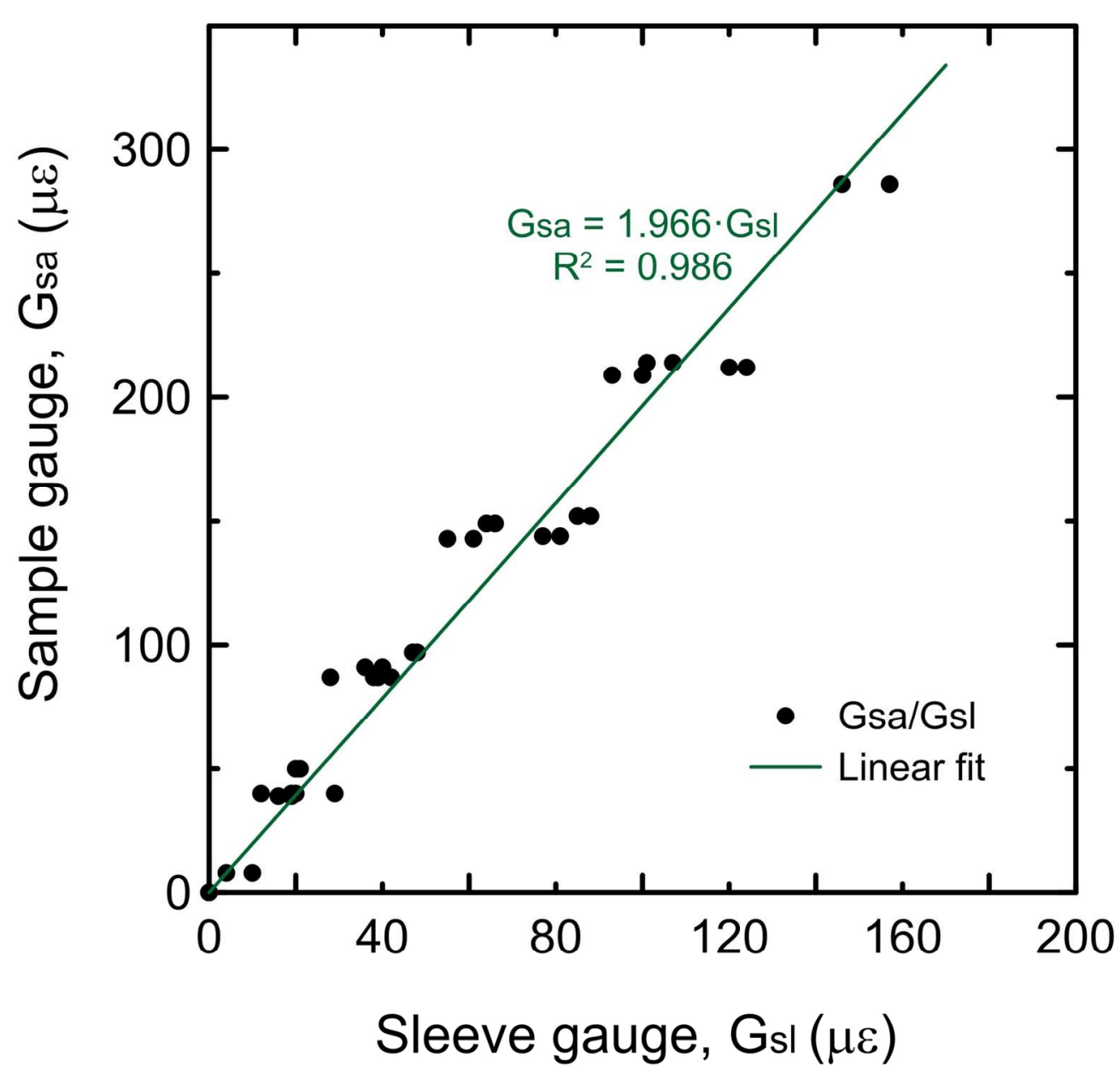

Figure 2. Axial strain calibration. $152 \times 142 \mathrm{~mm}(300 \times 300 \mathrm{DPI})$ 


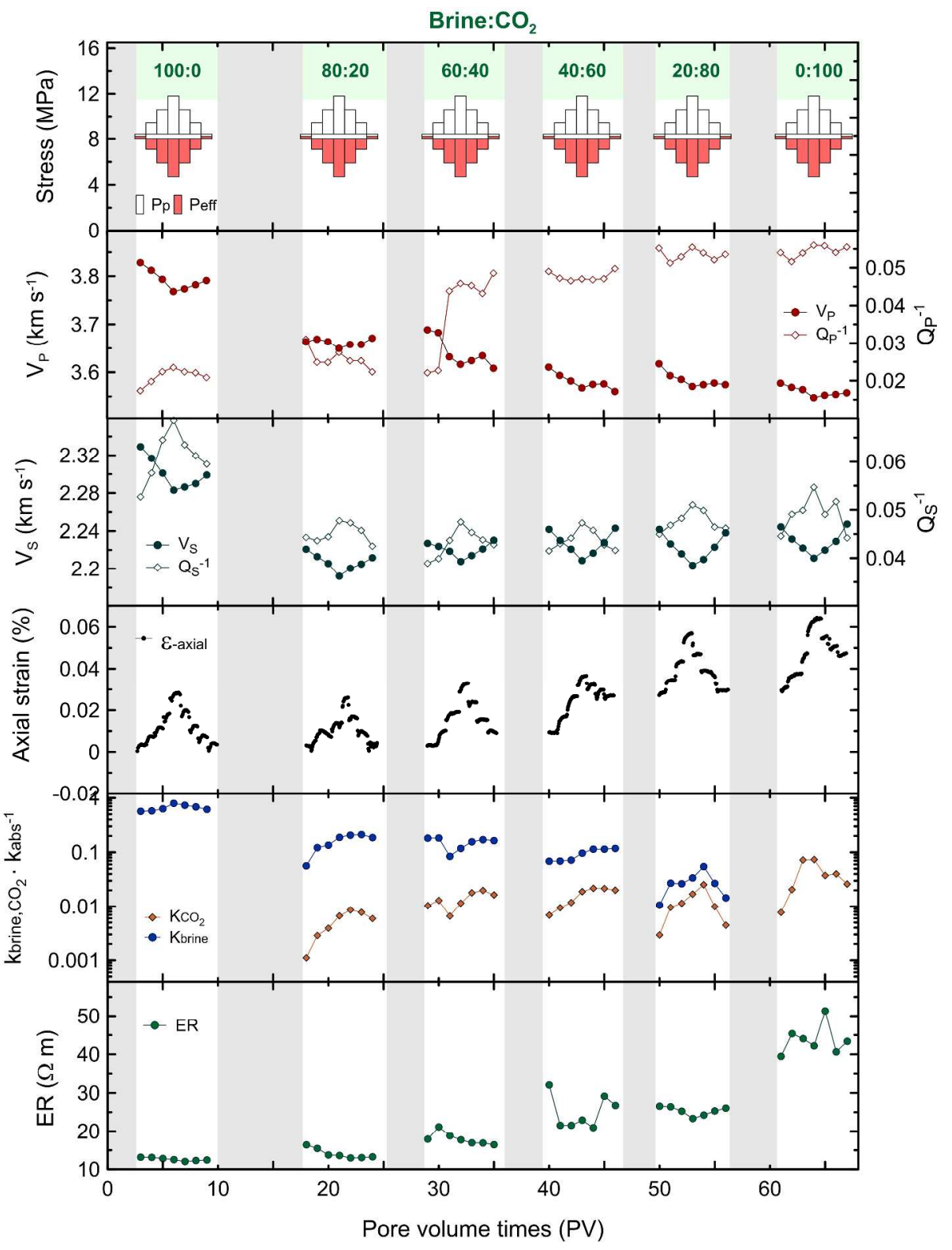

Figure 3. Six fractional flows brine: $\mathrm{CO}_{2}$ flooding test. $\mathrm{P}$ - and $\mathrm{S}$-wave velocities $\left(\mathrm{V}_{\mathrm{p}}, \mathrm{V}_{\mathrm{s}}\right)$ and attenuation (by the inverse quality factors $\mathrm{Q}_{p}{ }^{-1}$ and $\mathrm{Q}_{s}{ }^{-1}$, respectively), axial strains ( $\left.\varepsilon_{\text {axial }}\right)$, relative permeability ( $\mathrm{k}_{\text {brine,co2}}$ ) and electrical resistivity (ER) against pore volume times $\left(P V \sim 10 \mathrm{~cm}^{3}\right)$. Geomechanical conditions defined by effective pressure, $\mathrm{P}_{\text {eff, }}$ and pore pressure, $\mathrm{P}_{\mathrm{p}}$. $417 \times 544 \mathrm{~mm}(300 \times 300 \mathrm{DPI})$ 

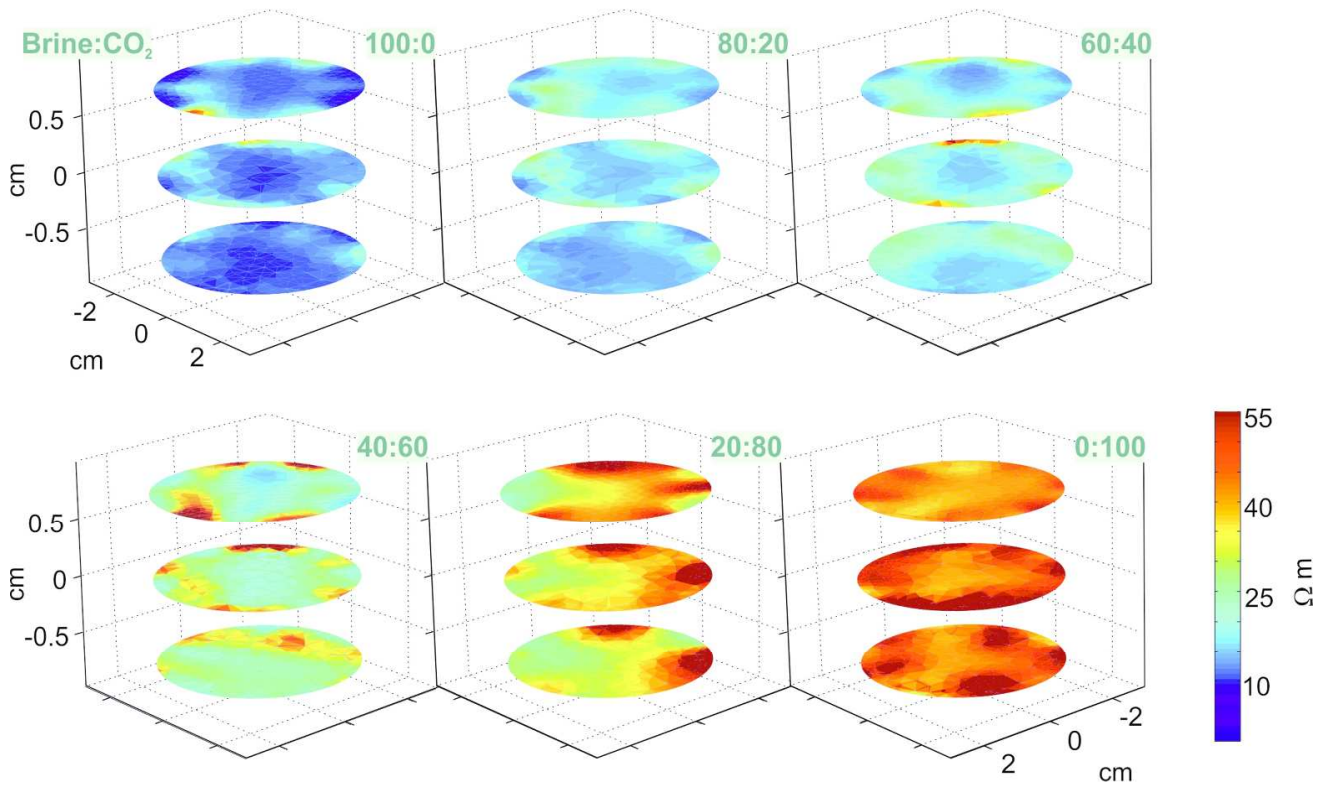

Figure 4. Electrical resistivity tomography for each fractional flow brine: $\mathrm{CO}_{2}$ stage. $197 \times 118 \mathrm{~mm}(300 \times 300 \mathrm{DPI})$ 


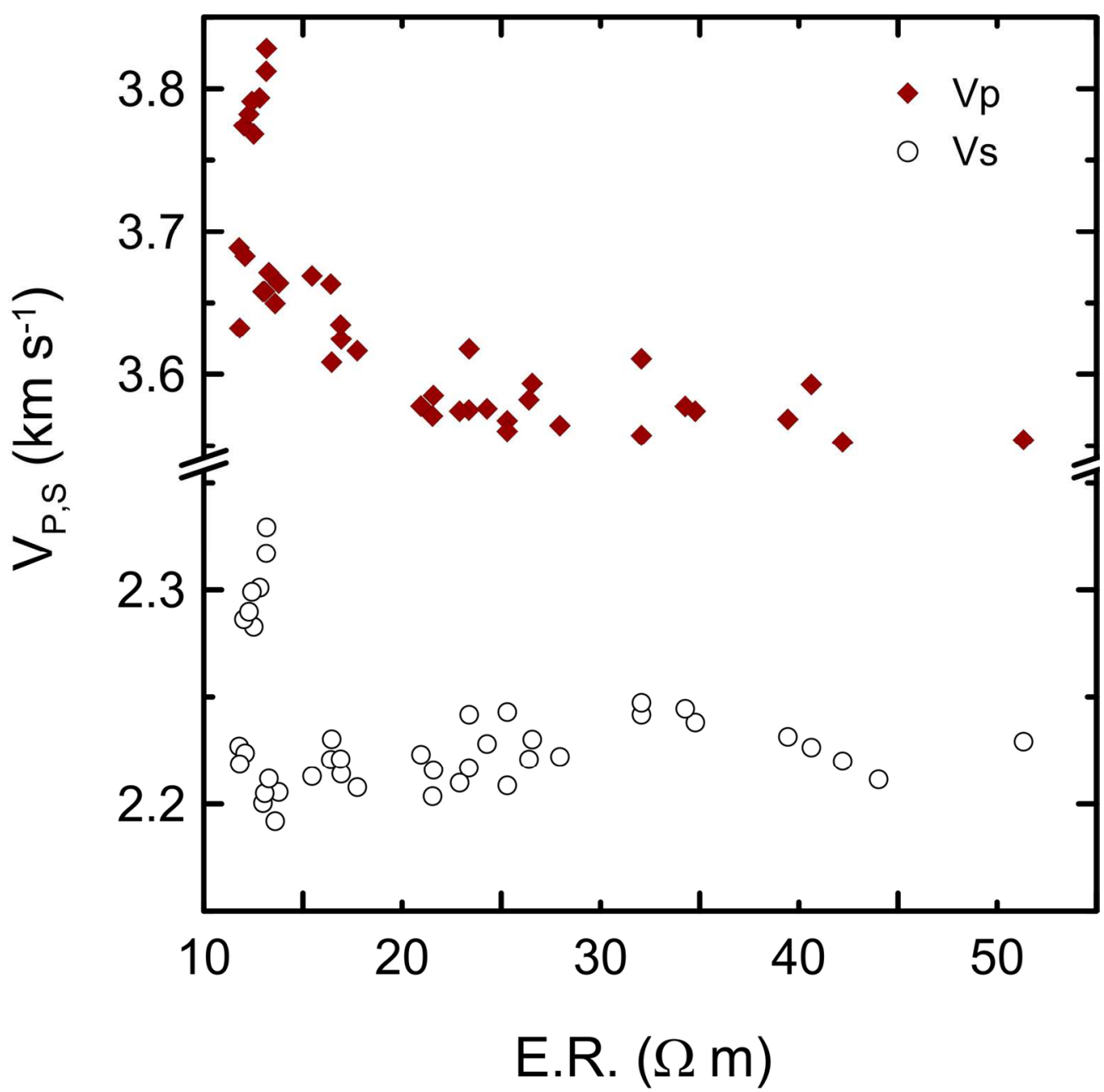

Figure 5. Acoustic wave velocities versus electrical resistivity. Experimental results. $152 \times 149 \mathrm{~mm}(300 \times 300 \mathrm{DPI})$ 


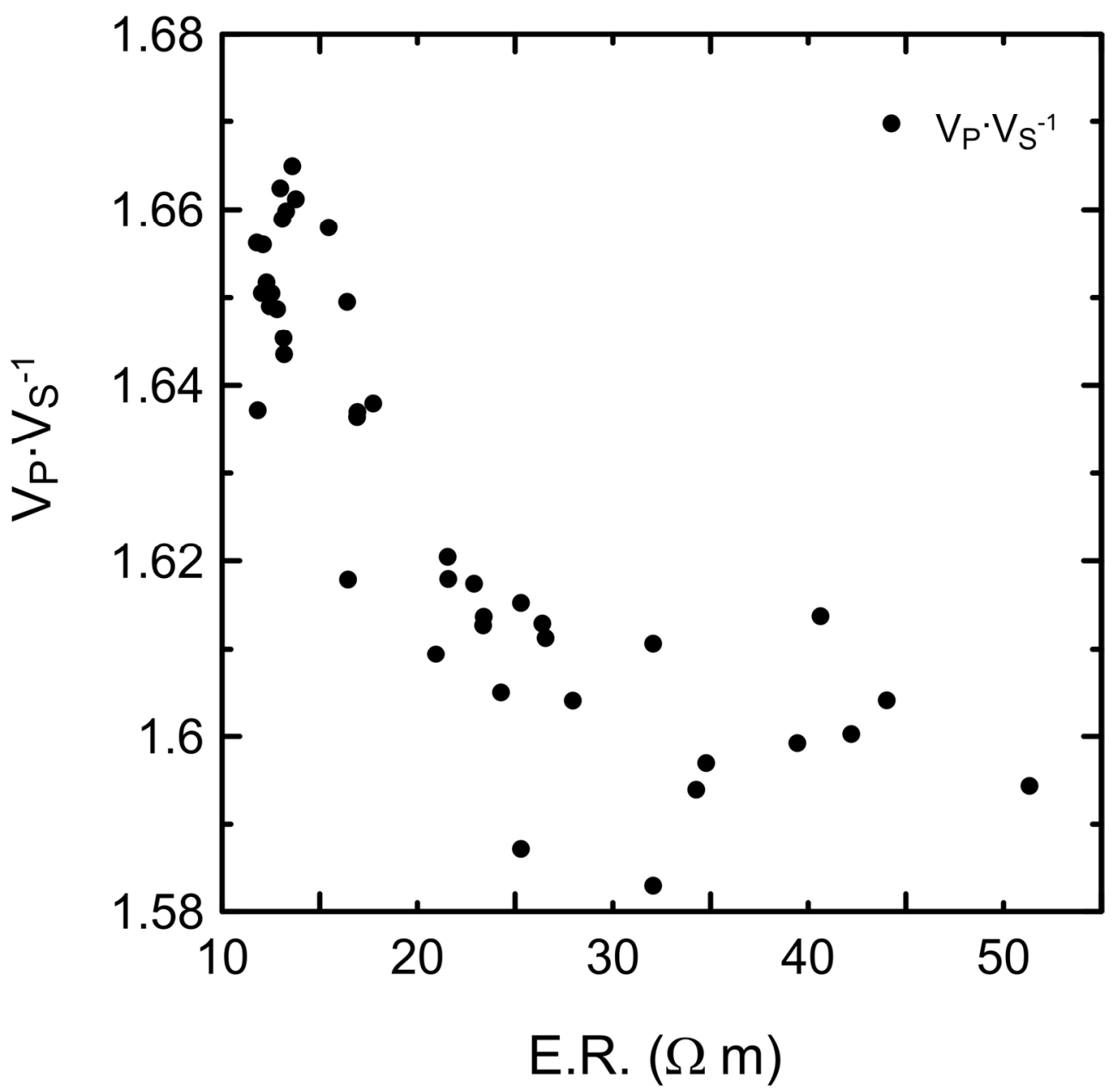

Figure 6. Acoustic wave velocity ratio $\mathrm{V}_{\mathrm{p}} \cdot \mathrm{V}_{\mathrm{s}}{ }^{-1}$ versus electrical resistivity. Experimental results. $156 \times 150 \mathrm{~mm}(300 \times 300 \mathrm{DPI})$ 


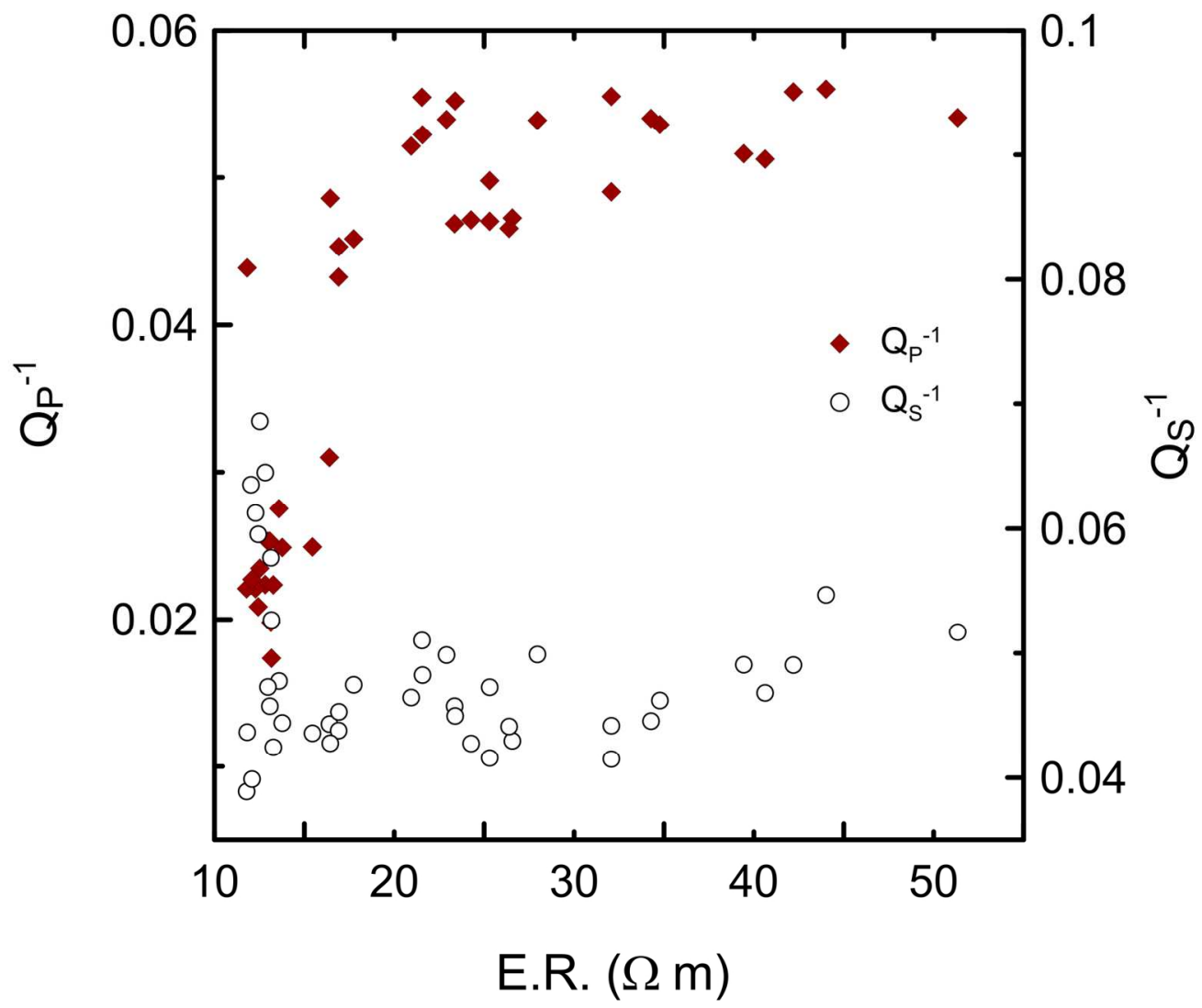

Figure 7. Acoustic wave attenuation factors versus electrical resistivity. Experimental results. $156 \times 129 \mathrm{~mm}(300 \times 300$ DPI $)$ 


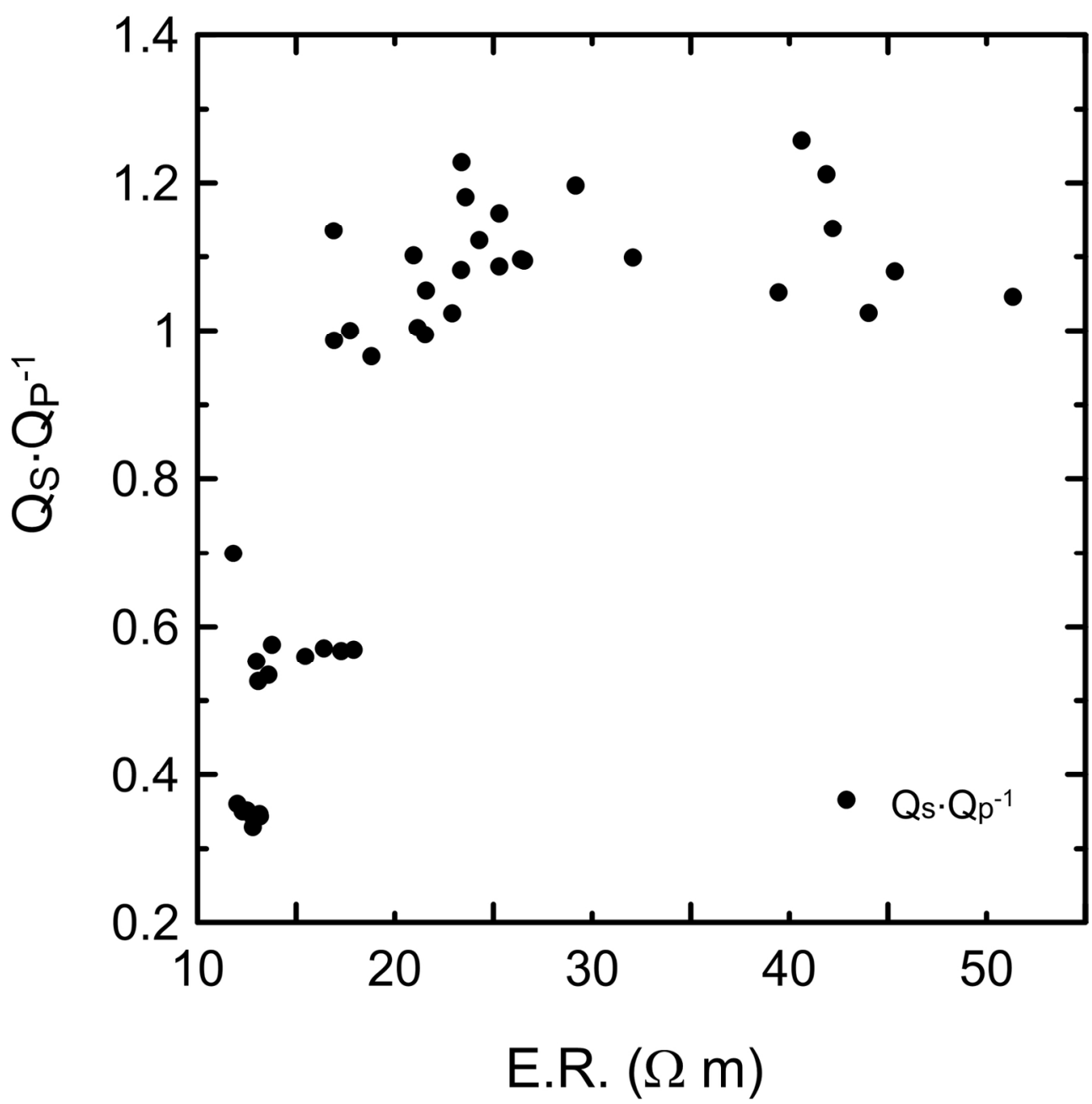

Figure 8. Acoustic wave attenuation ratio $\mathrm{Q}_{s} \cdot \mathrm{Q}_{\mathrm{p}}{ }^{-1}$ versus electrical resistivity. Experimental results. $156 \times 155 \mathrm{~mm}(300 \times 300 \mathrm{DPI})$ 


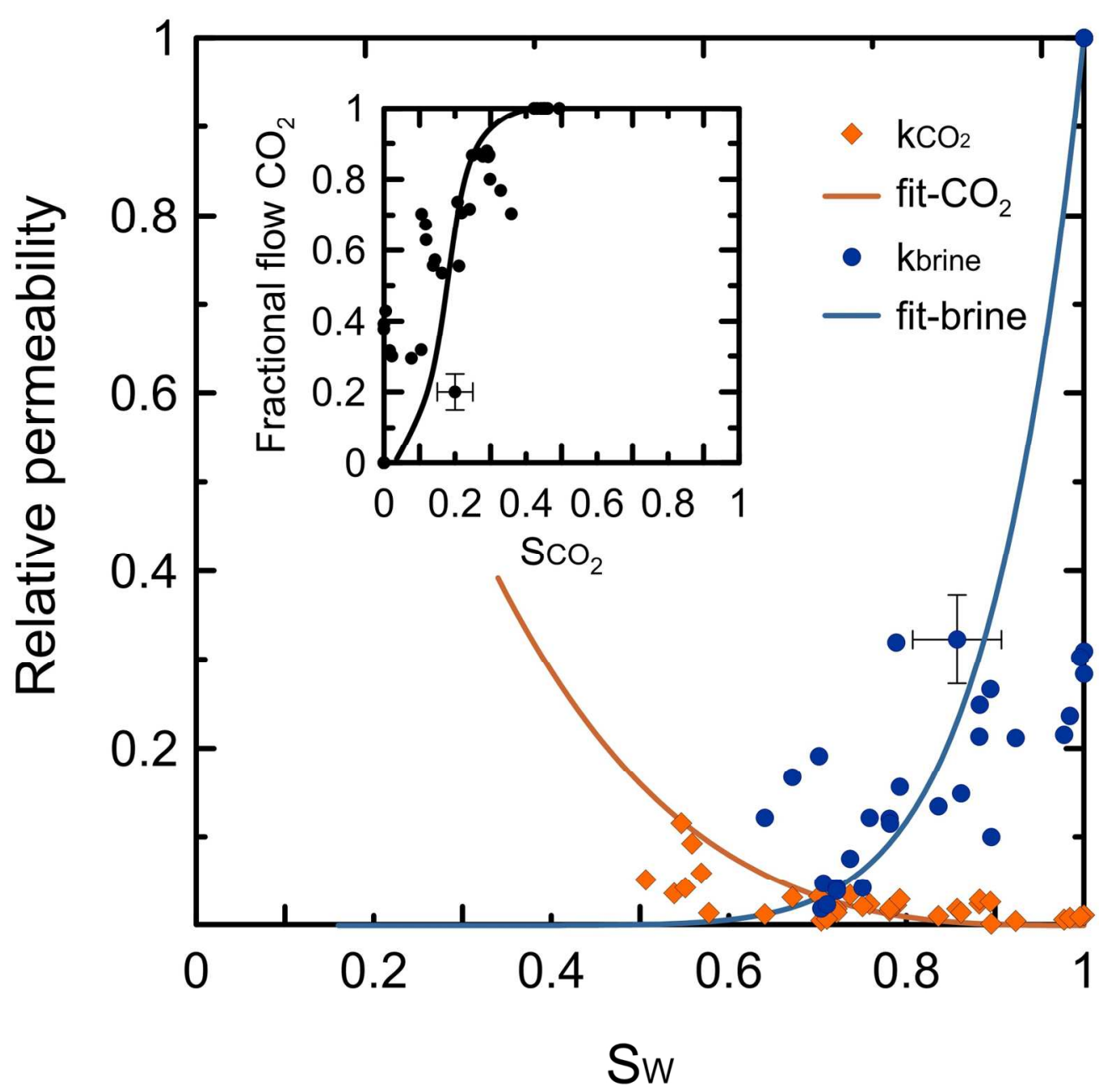

Figure 9. Brine- $\mathrm{CO}_{2}$ relative permeability. Corey fitting: $\mathrm{S}_{\mathrm{wr}}=0.15, \mathrm{~N}_{\mathrm{w}}=7$ and $\mathrm{N}_{\mathrm{CO2}}=0.5$; inner plot represents fractional flow evolution with $\mathrm{CO}_{2}$ saturation. $155 \times 154 \mathrm{~mm}(300 \times 300 \mathrm{DPI})$ 


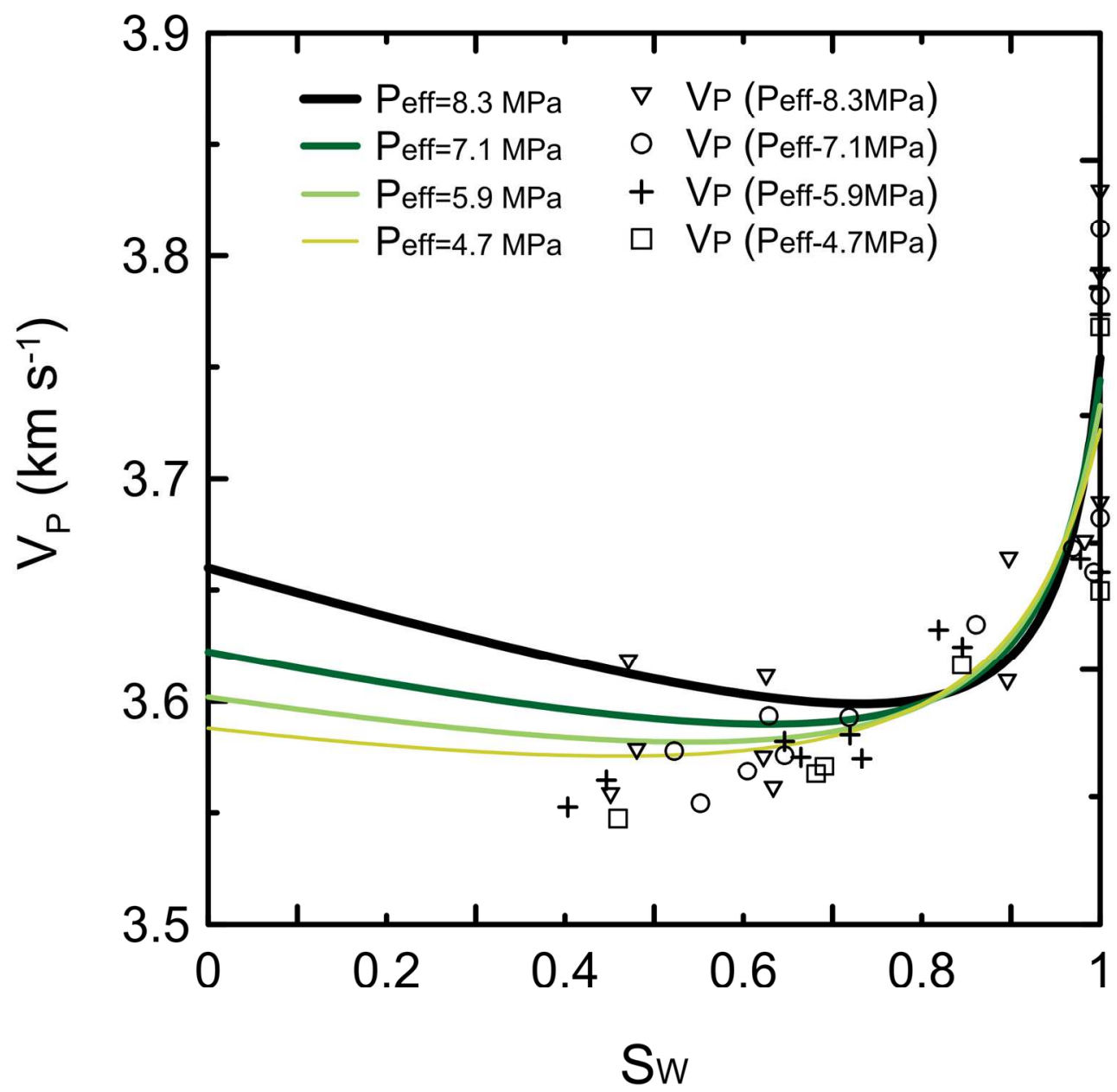

Figure 10. Gassmann's model prediction and observed $V_{p}$ for the four effective pressure steps of the test. $155 \times 150 \mathrm{~mm}(300 \times 300 \mathrm{DPI})$ 


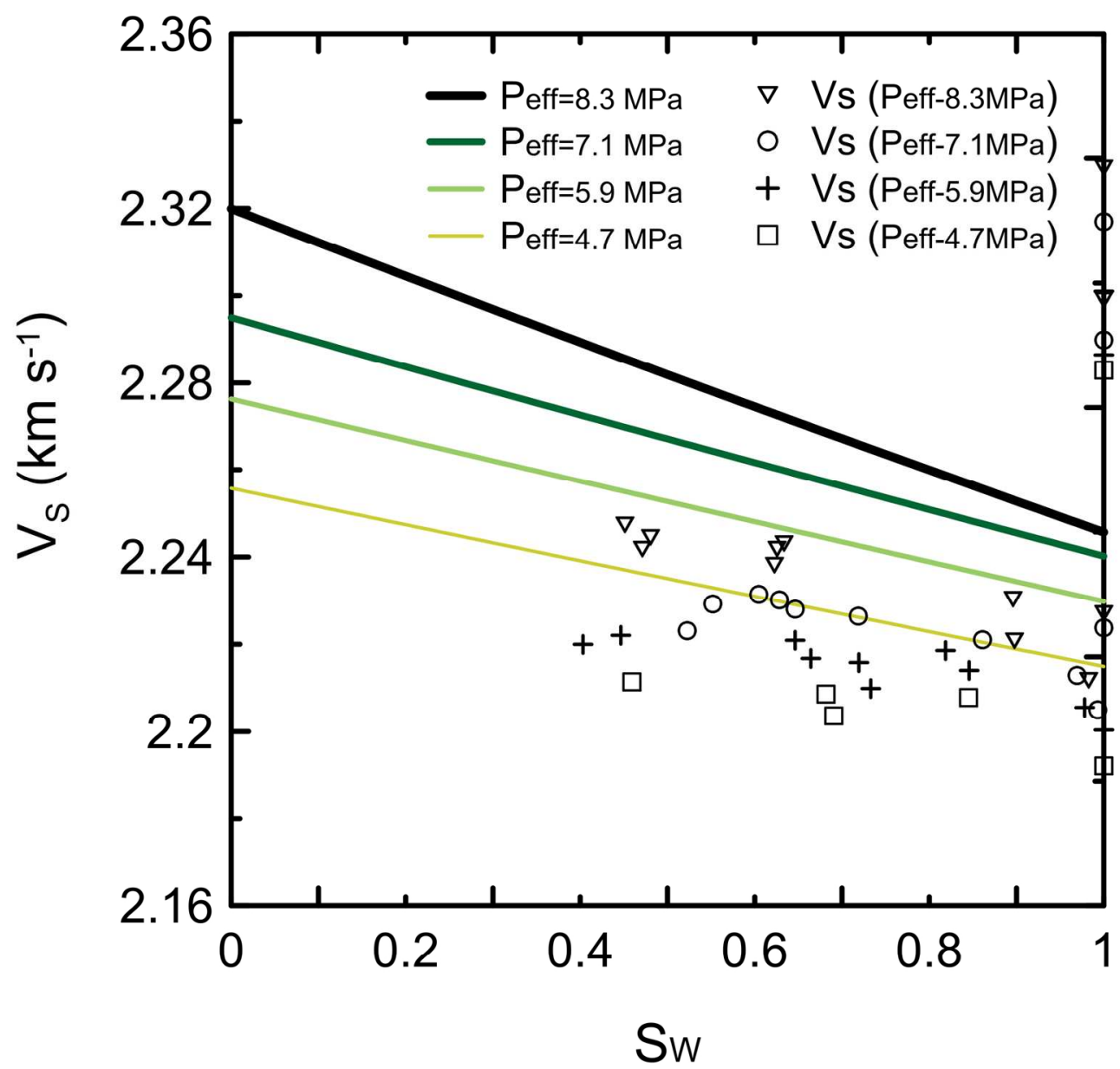

Figure 11. Gassmann's model prediction and observed $\mathrm{V}_{\mathrm{s}}$ for the four effective pressure steps of the test. $155 \times 146 \mathrm{~mm}(300 \times 300 \mathrm{DPI})$ 


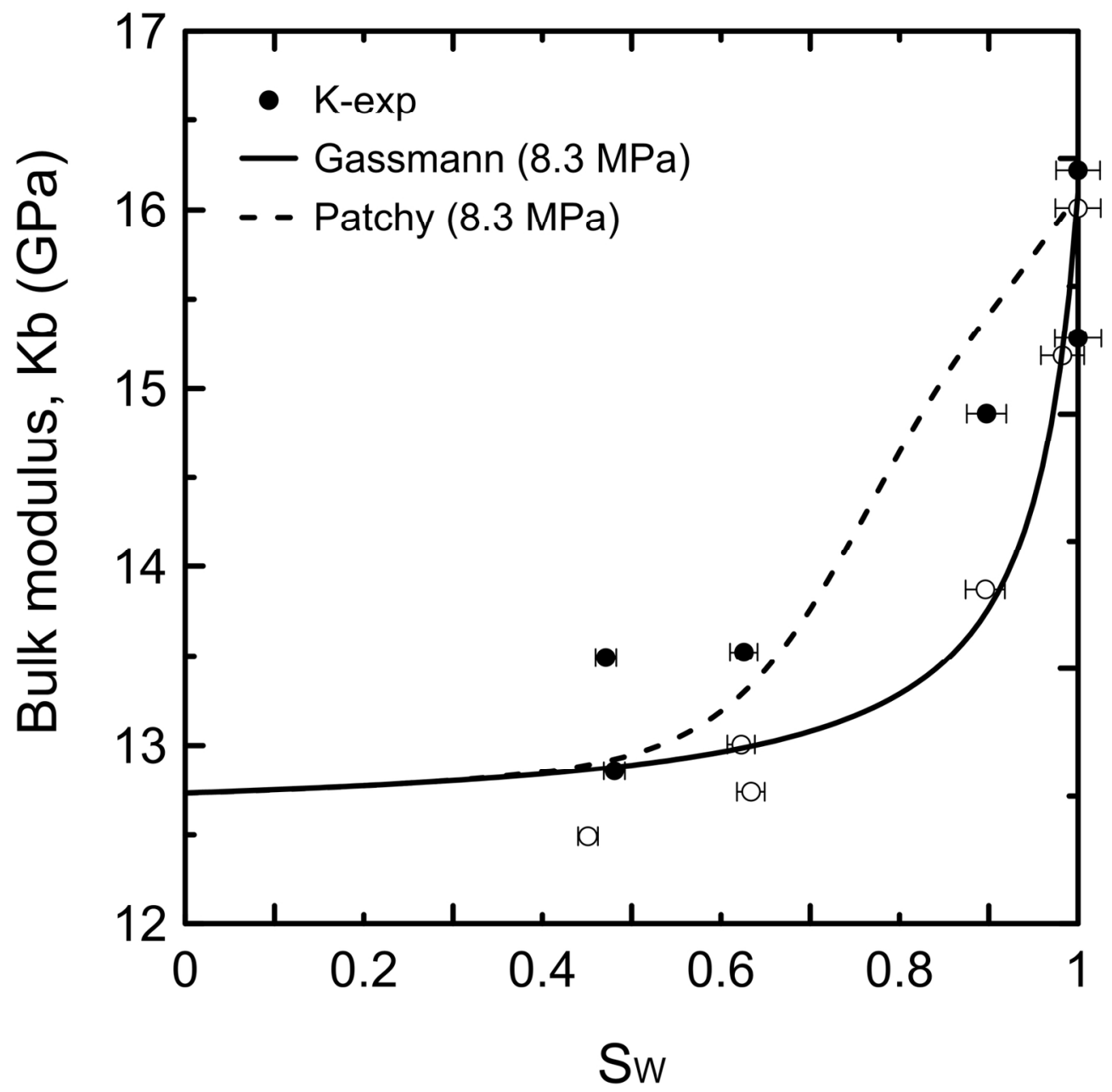

Figure 12a. Bulk modulus $\mathrm{K}_{\mathrm{b}}$ validation by Gassmann and Patchy models the four effective pressure of the test $P_{\text {eff }}=8.3 \mathrm{MPa}$ $155 \times 153 \mathrm{~mm}(300 \times 300 \mathrm{DPI})$ 


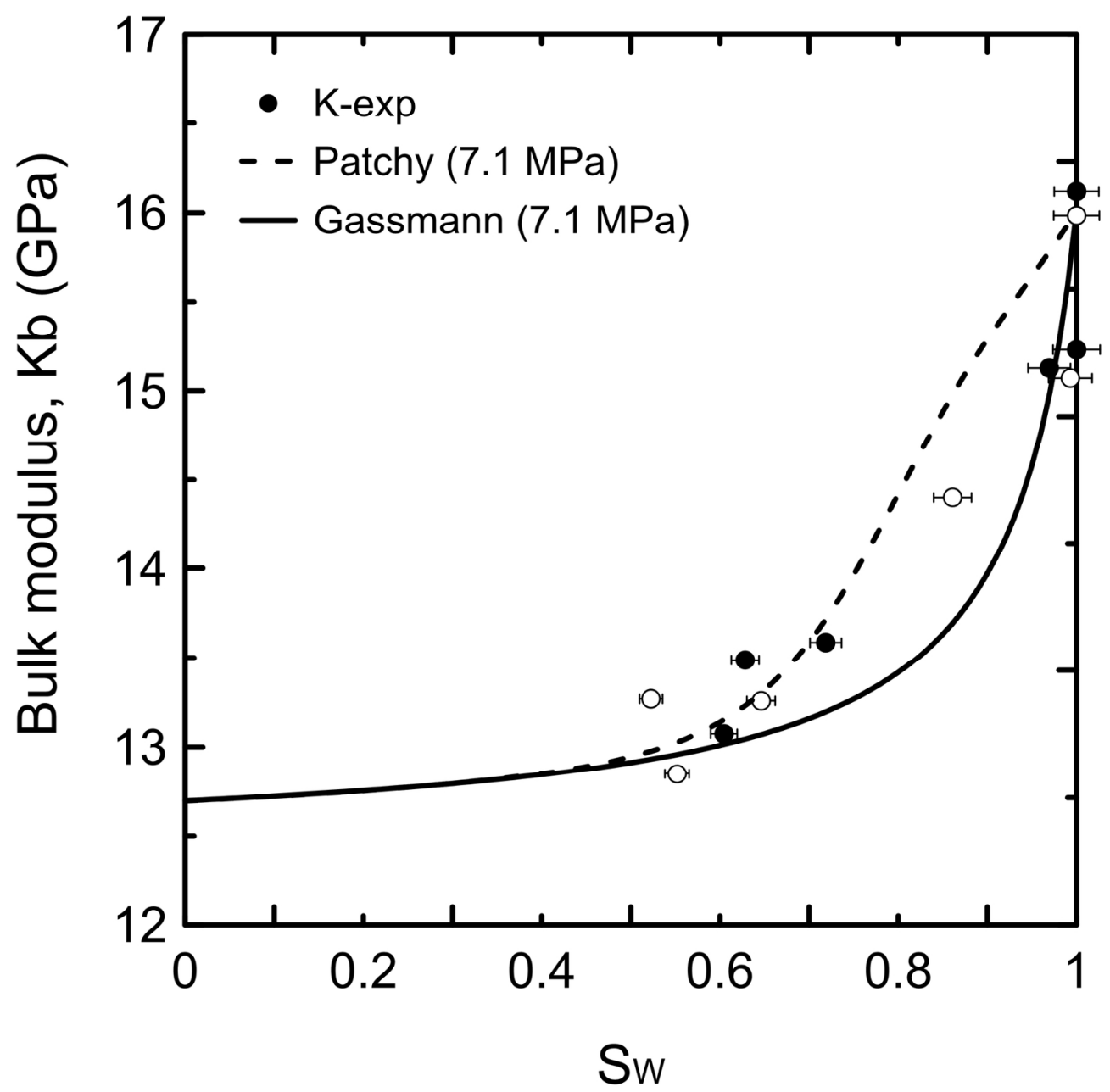

Figure 12b. Bulk modulus $\mathrm{K}_{\mathrm{b}}$ validation by Gassmann and Patchy models the four effective pressure of the test $P_{\text {eff }}=7.1 \mathrm{MPa}$ $155 \times 153 \mathrm{~mm}(300 \times 300 \mathrm{DPI})$ 


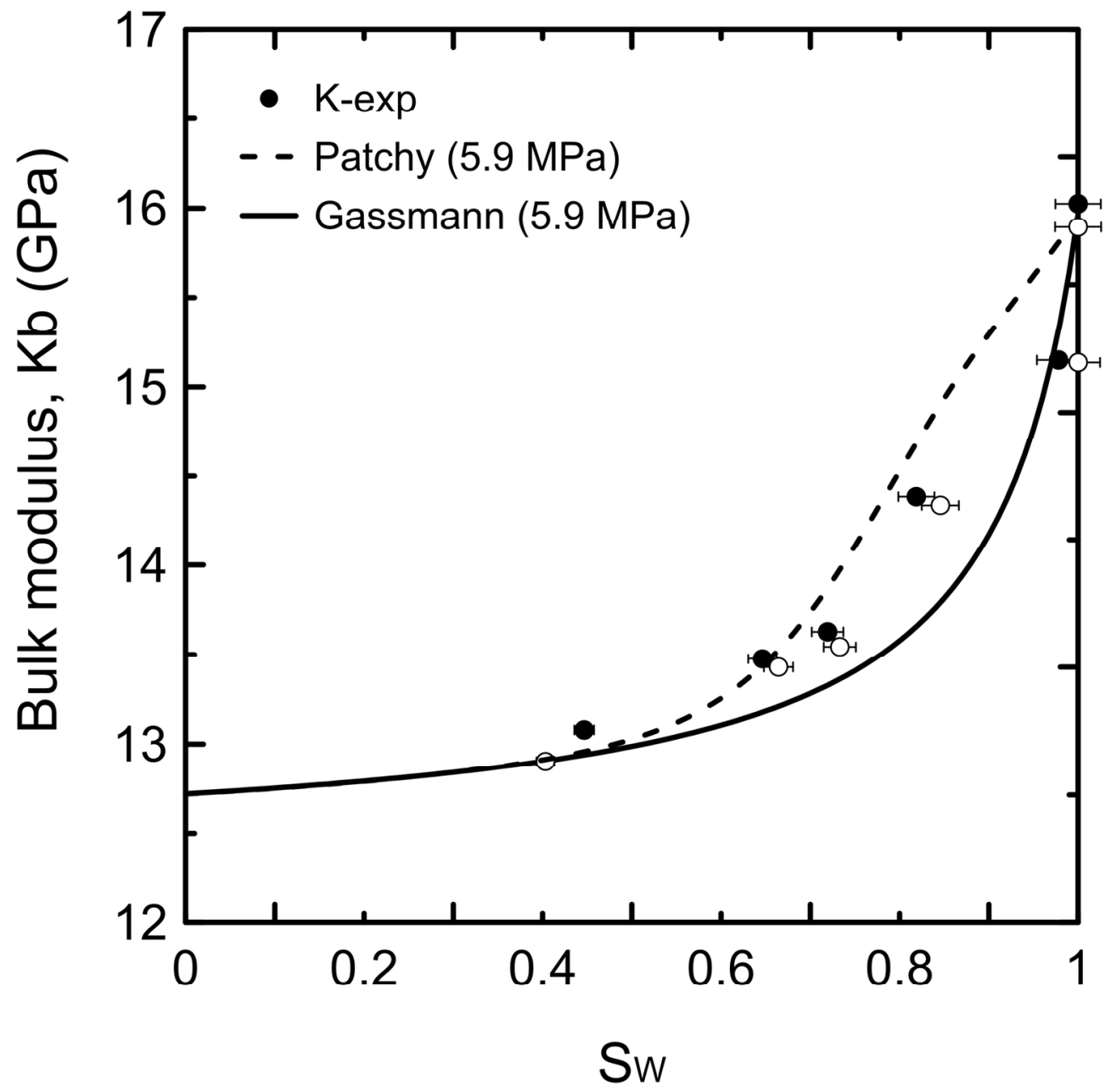

Figure 12c. Bulk modulus $\mathrm{K}_{\mathrm{b}}$ validation by Gassmann and Patchy models the four effective pressure of the test $P_{\text {eff }}=5.9 \mathrm{MPa}$ $155 \times 153 \mathrm{~mm}(300 \times 300 \mathrm{DPI})$ 


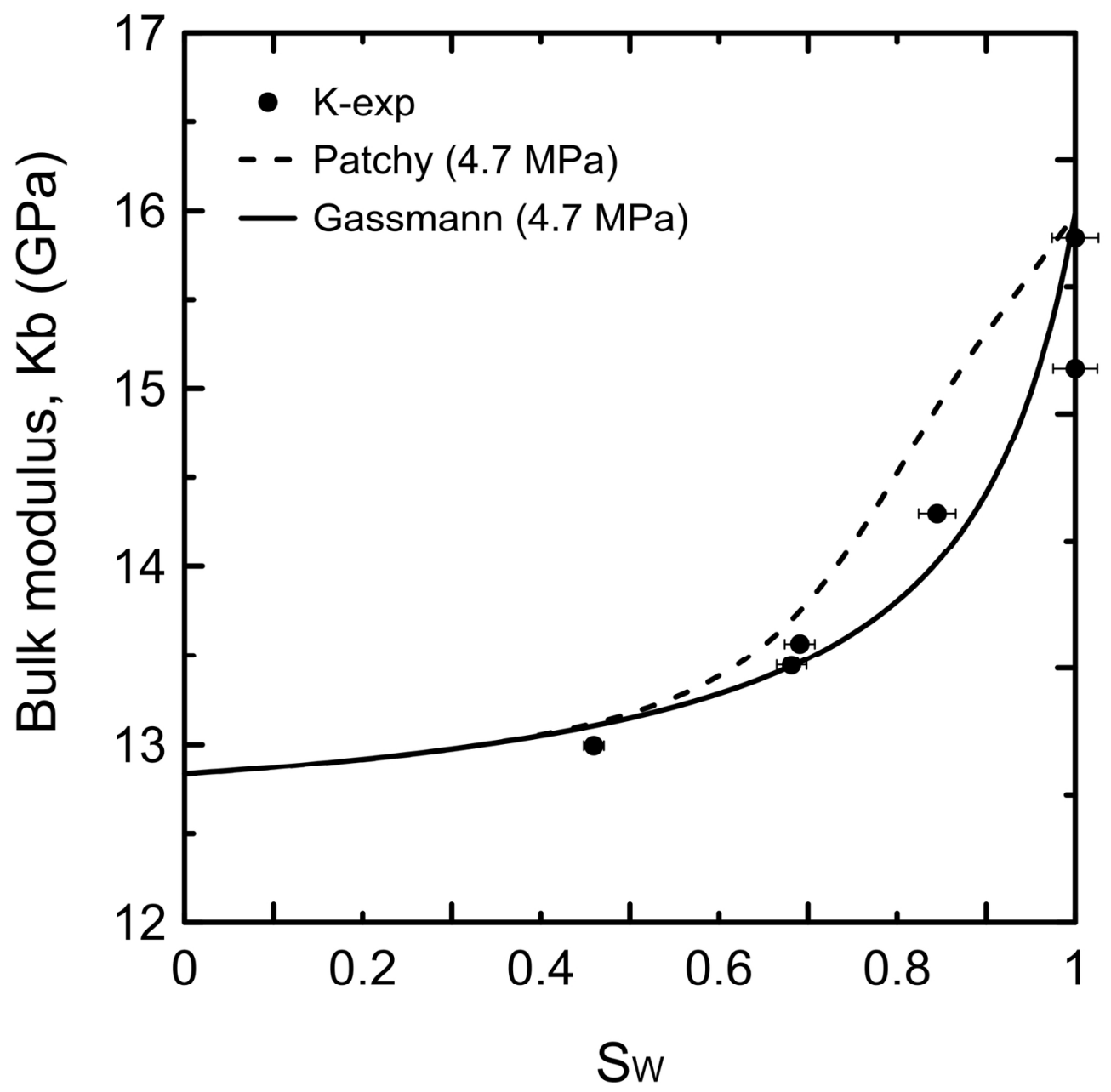

Figure 12d. Bulk modulus $\mathrm{K}_{\mathrm{b}}$ validation by Gassmann and Patchy models the four effective pressure of the test $P_{\text {eff }}=4.7 \mathrm{MPa}$ $155 \times 152 \mathrm{~mm}(300 \times 300$ DPI $)$ 


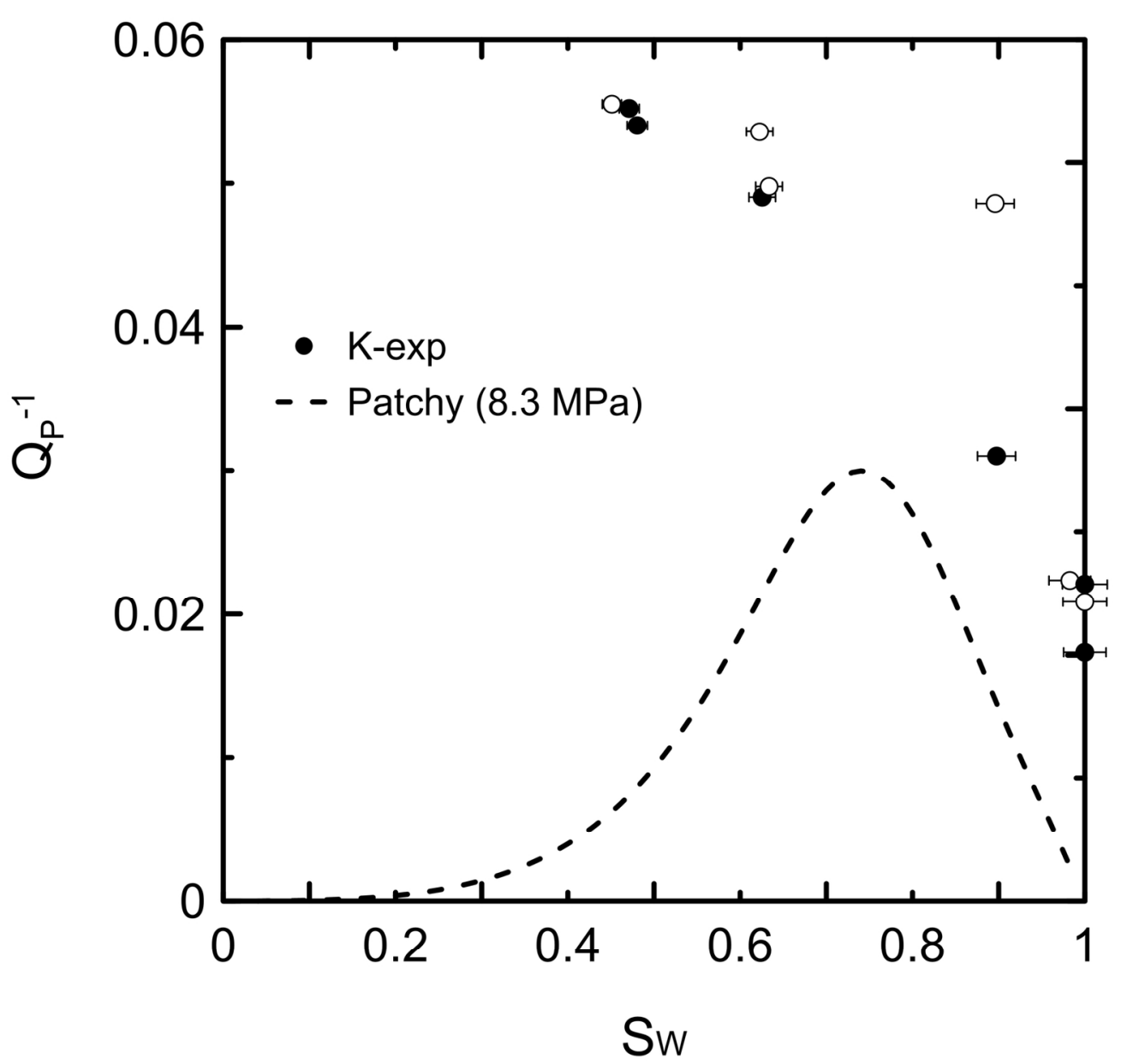

Figure 13a. P-wave attenuation $\mathrm{Q}_{p}{ }^{-1}$ versus brine saturation for the four effective pressure of the test, at $\mathrm{P}_{\text {eff }}$ $=8.3 \mathrm{MPa}$. Experimental data shown by open circles (loading) and solid circles (unloading). $155 \times 146 \mathrm{~mm}(300 \times 300 \mathrm{DPI})$ 


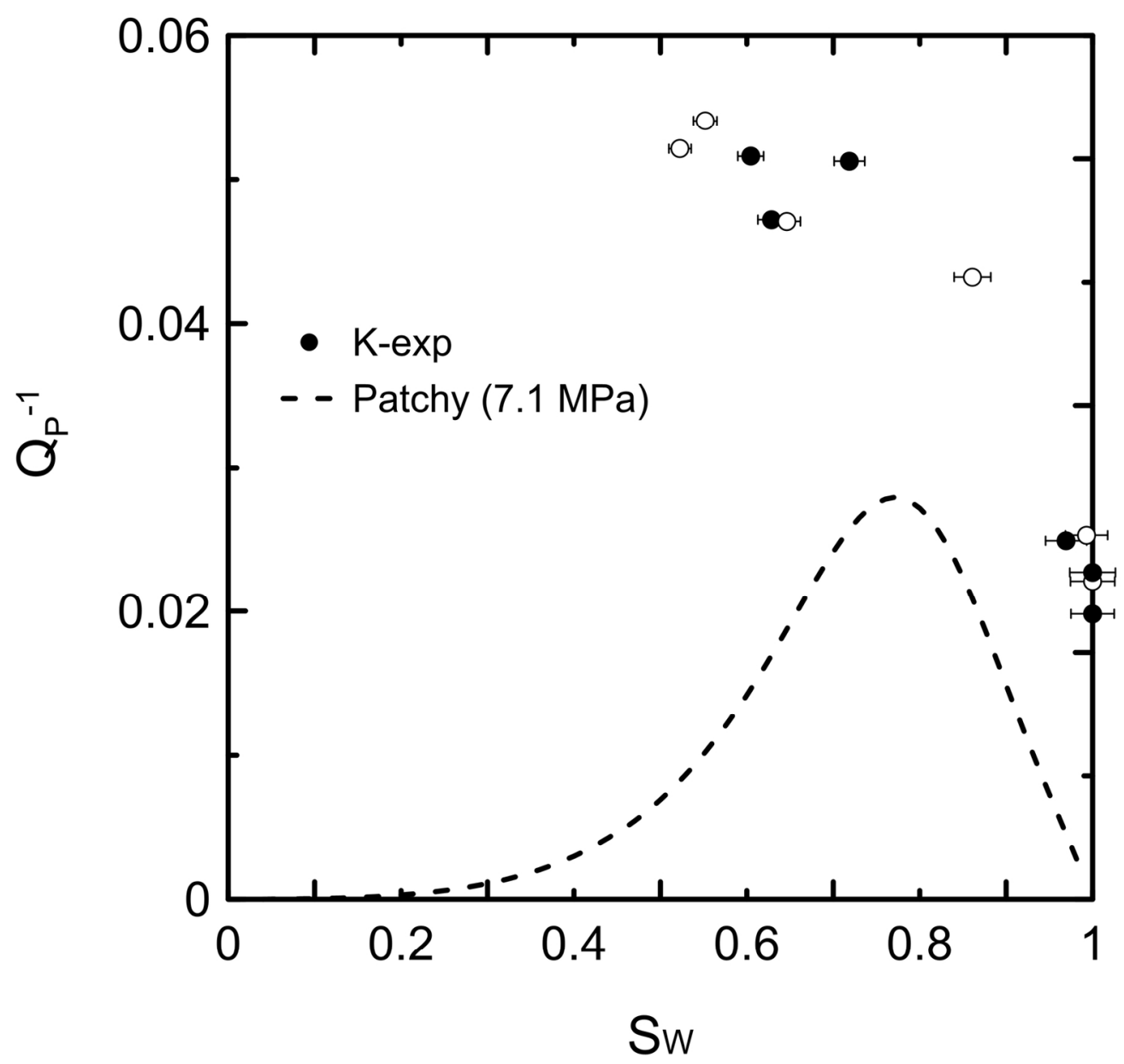

Figure 13b. P-wave attenuation $\mathrm{Q}_{\mathrm{p}}{ }^{-1}$ versus brine saturation for the four effective pressure of the test, at $\mathrm{P}_{\text {eff }}$ = 7.1 MPa. Experimental data shown by open circles (loading) and solid circles (unloading). $155 \times 147 \mathrm{~mm}(300 \times 300$ DPI $)$ 


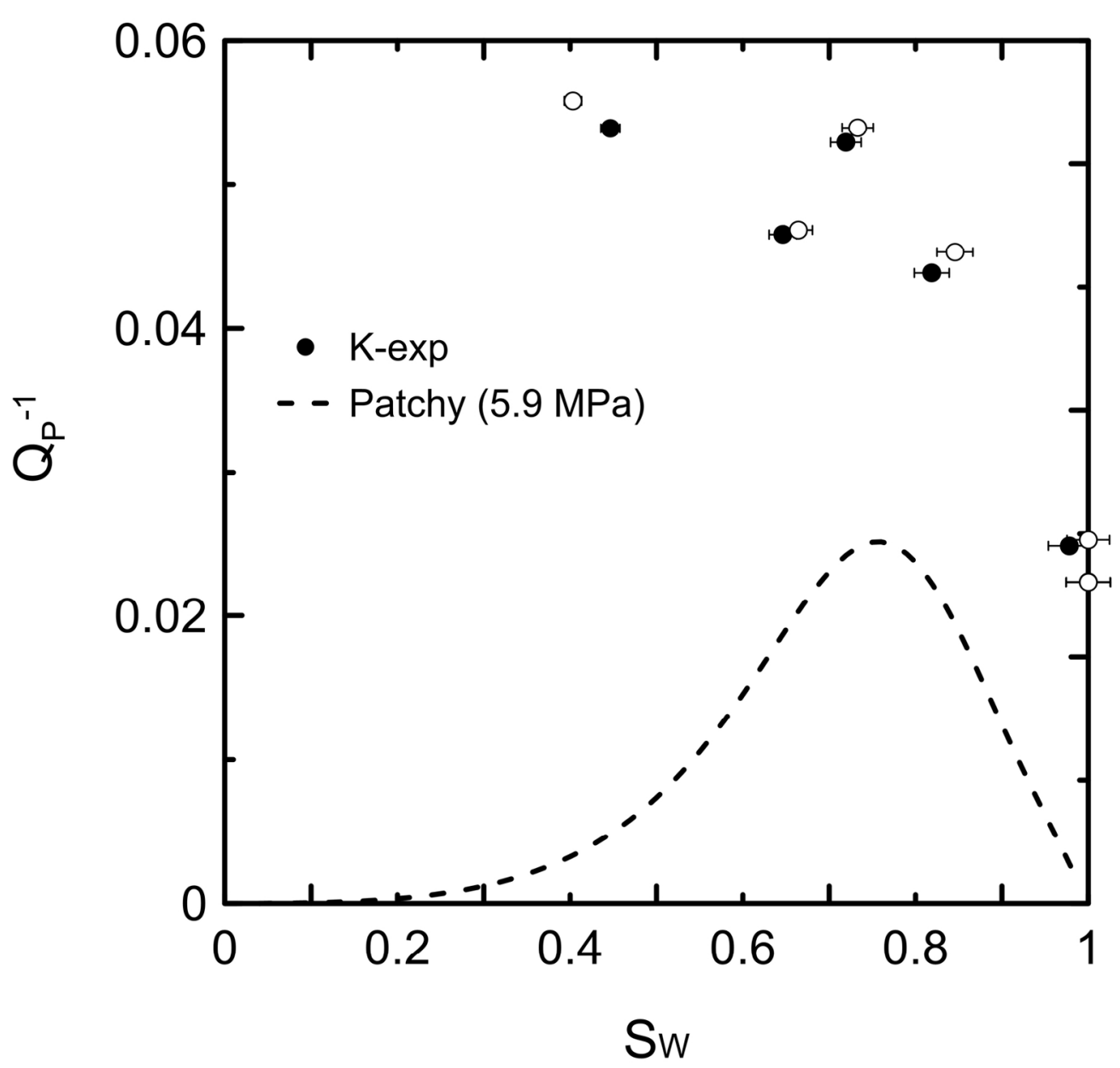

Figure 13c. P-wave attenuation $\mathrm{Q}_{\mathrm{p}}{ }^{-1}$ versus brine saturation for the four effective pressure of the test, at $\mathrm{P}_{\text {eff }}$ $=5.9 \mathrm{MPa}$. Experimental data shown by open circles (loading) and solid circles (unloading). $155 \times 147 \mathrm{~mm}(300 \times 300 \mathrm{DPI})$ 


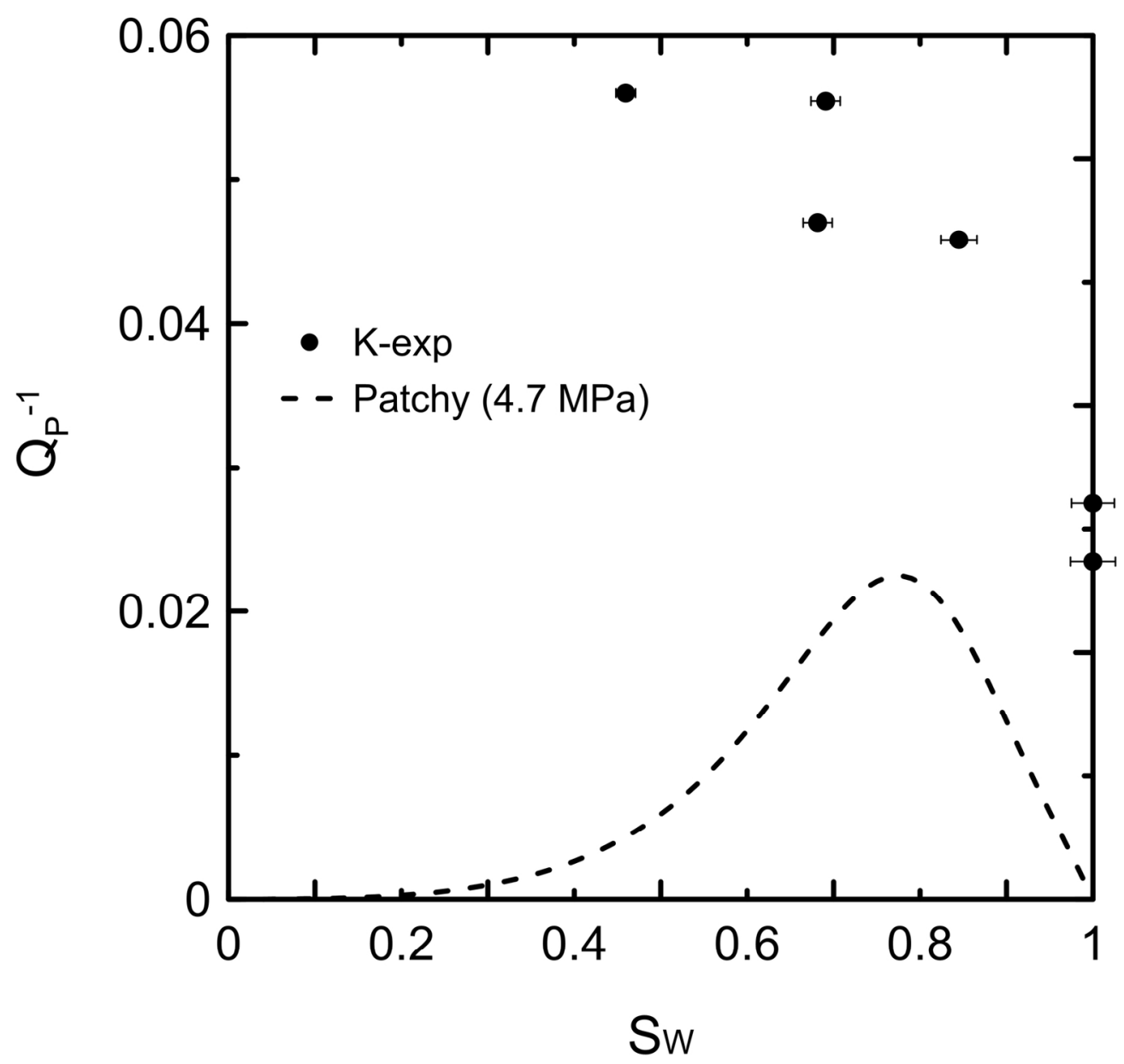

Figure 13d. P-wave attenuation $\mathrm{Q}_{\mathrm{p}}{ }^{-1}$ versus brine saturation for the four effective pressure of the test, at $\mathrm{P}_{\text {eff }}$ $=4.7 \mathrm{MPa}$. Experimental data shown by open circles (loading) and solid circles (unloading). $155 \times 147 \mathrm{~mm}(300 \times 300$ DPI $)$ 


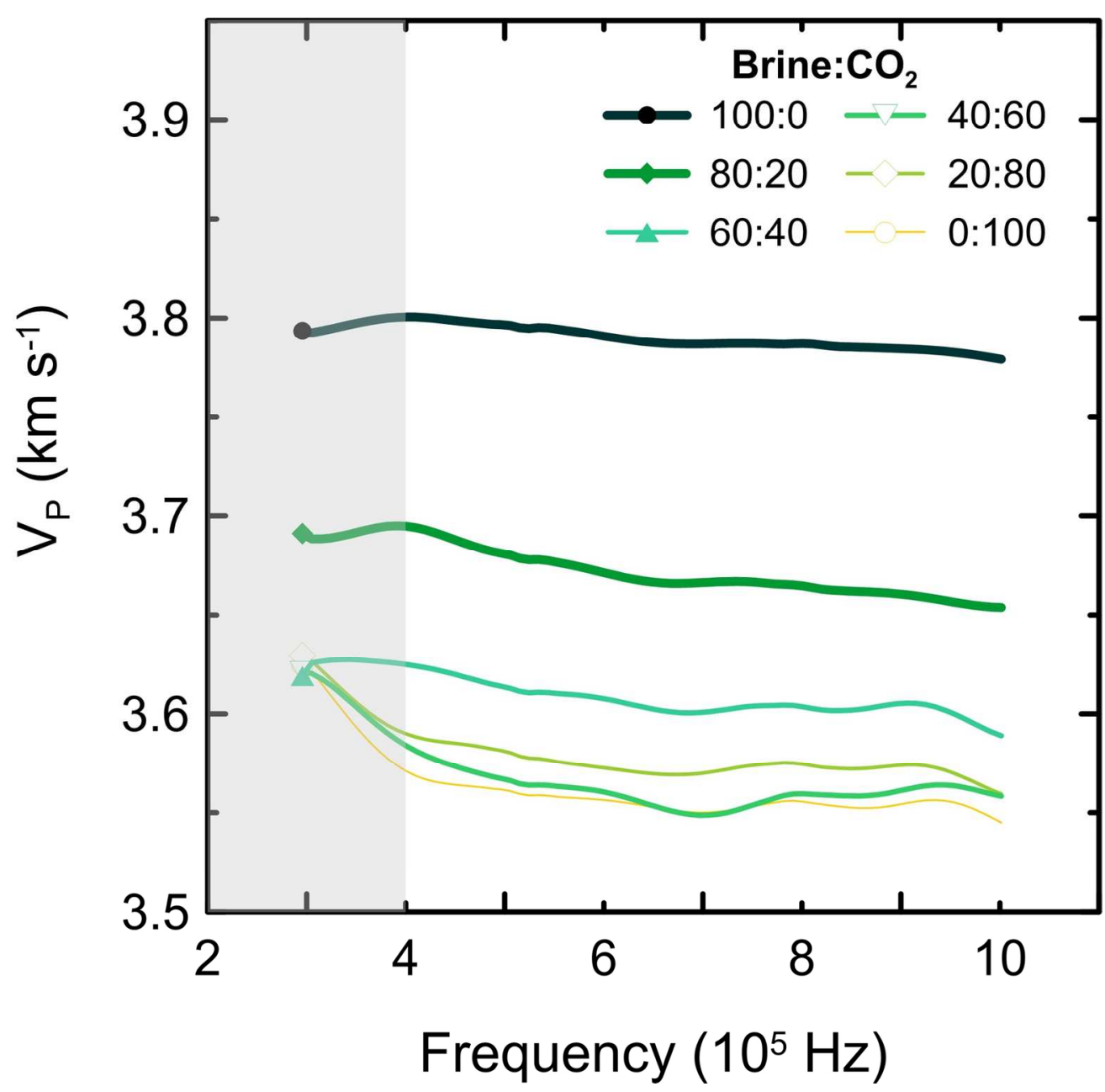

Figure 14a. P-wave velocity in the frequency range 3-10 kHz, for the six fractional flows brine: $\mathrm{CO}_{2}$. The examples correspond to the experimental data at $\mathrm{P}_{\text {eff }}=4.7 \mathrm{MPa}$. $151 \times 147 \mathrm{~mm}(300 \times 300 \mathrm{DPI})$ 


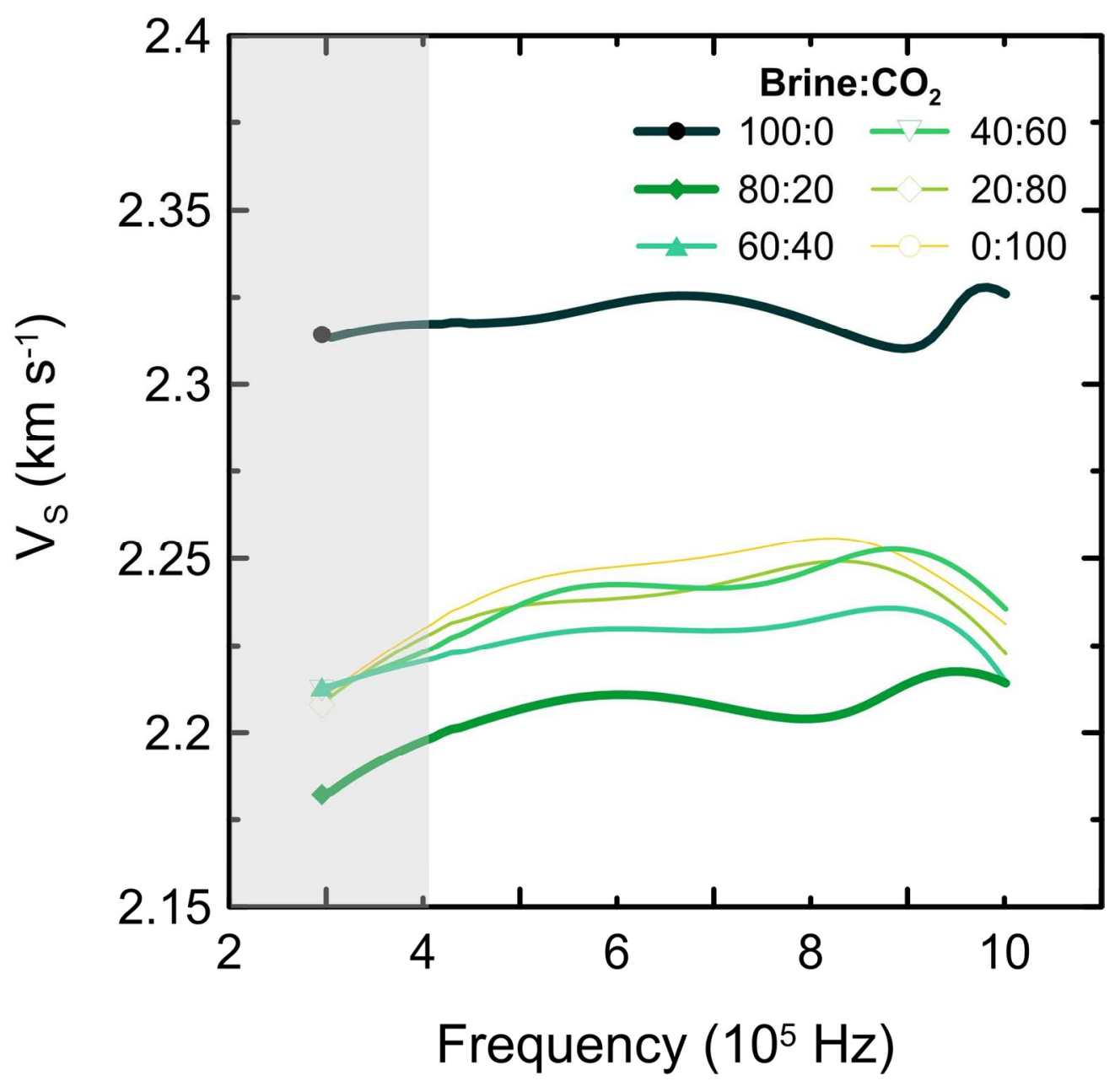

Figure 14b. S-wave velocity in the frequency range 3-10 kHz, for the six fractional flows brine: $\mathrm{CO}_{2}$. The examples correspond to the experimental data at $\mathrm{P}_{\mathrm{eff}}=4.7 \mathrm{MPa}$. $155 \times 150 \mathrm{~mm}(300 \times 300 \mathrm{DPI})$ 


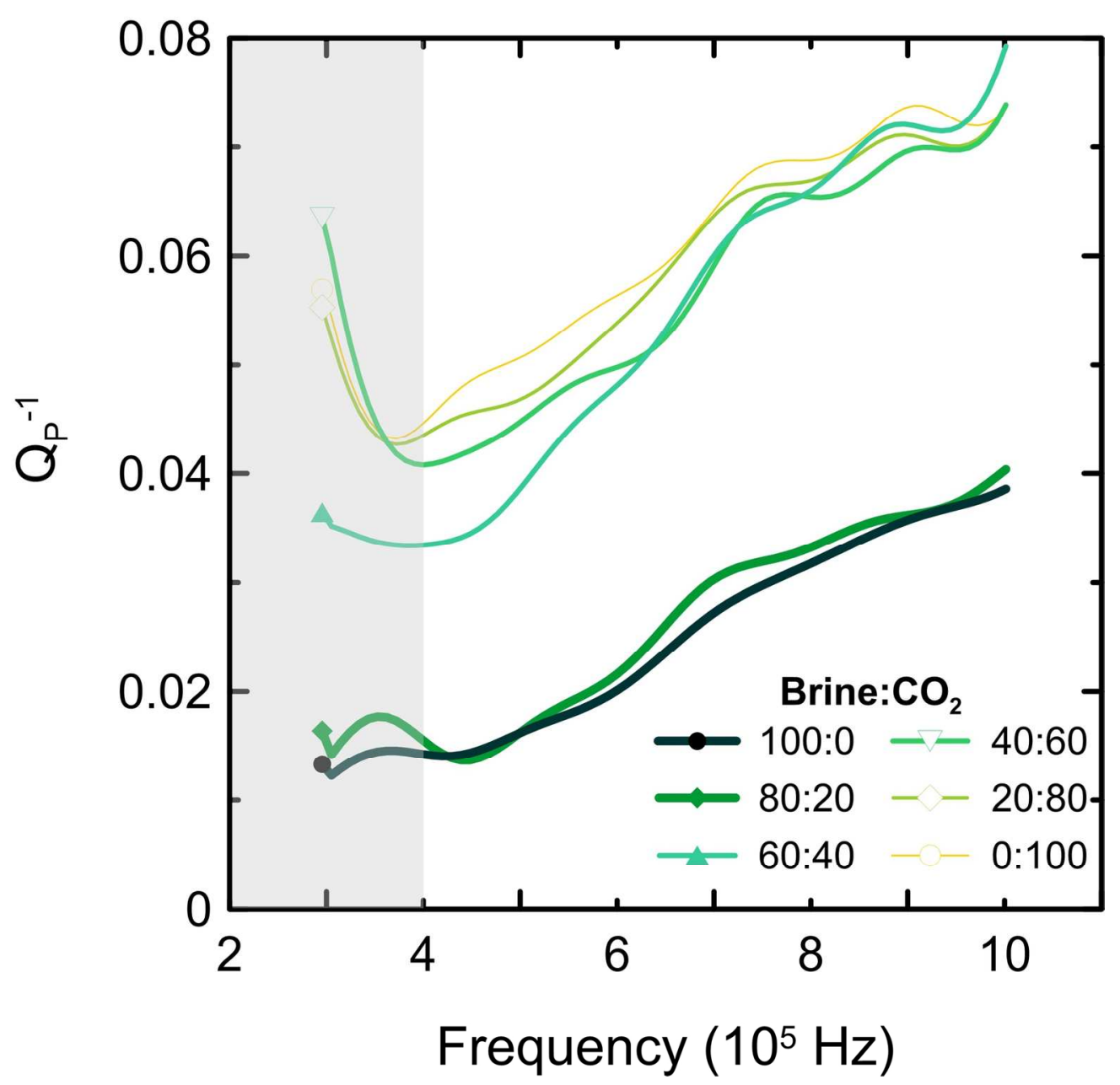

Figure 14c. P-wave attenuation in the frequency range $3-10 \mathrm{kHz}$, for the six fractional flows brine: $\mathrm{CO}_{2}$. The examples correspond to the experimental data at $\mathrm{P}_{\text {eff }}=4.7 \mathrm{MPa}$. $155 \times 150 \mathrm{~mm}(300 \times 300 \mathrm{DPI})$ 


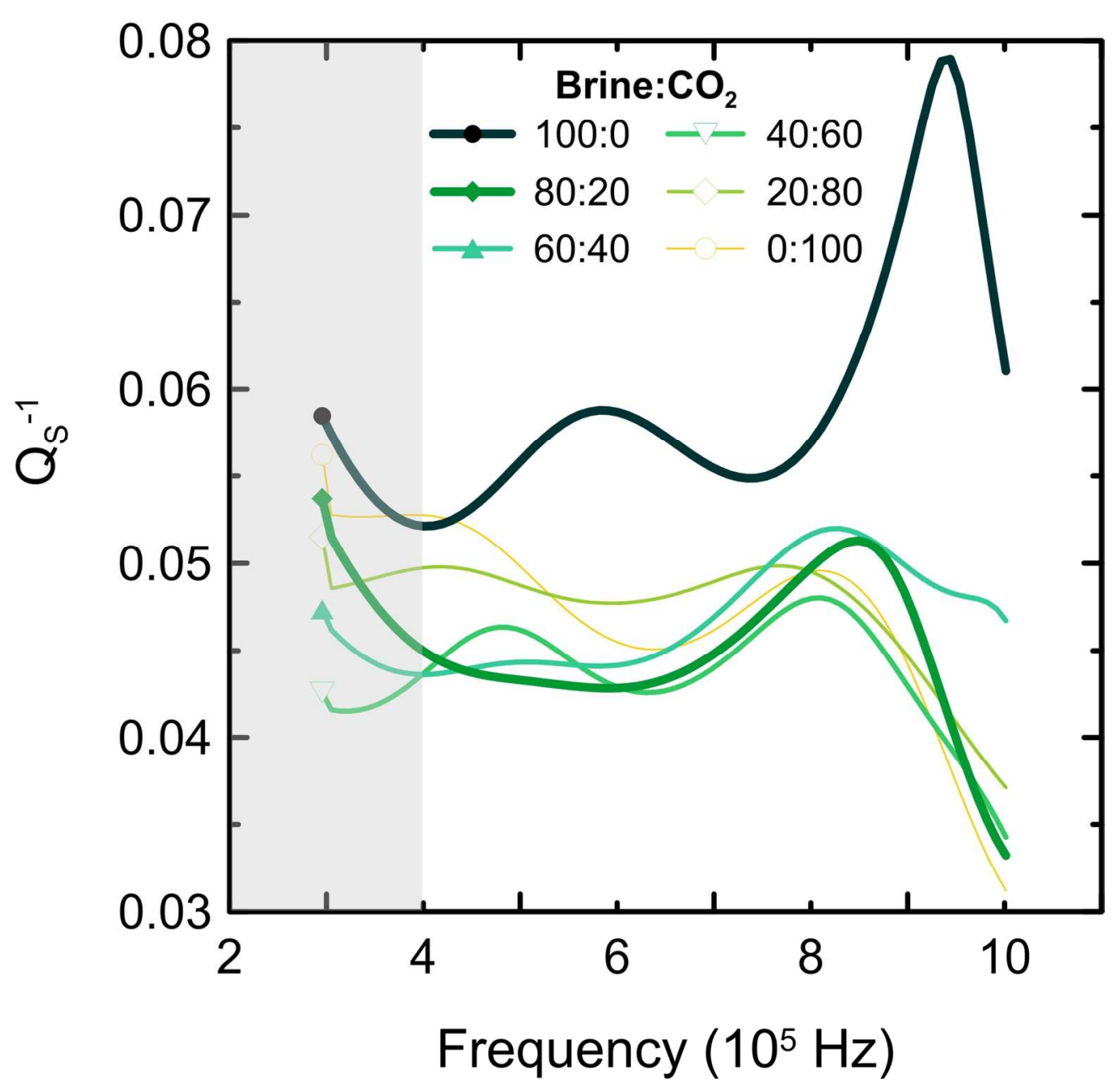

Figure 14d. S-wave attenuation in the frequency range $3-10 \mathrm{kHz}$, for the six fractional flows brine: $\mathrm{CO}_{2}$. The examples correspond to the experimental data at $\mathrm{P}_{\text {eff }}=4.7 \mathrm{MPa}$. $155 \times 150 \mathrm{~mm}(300 \times 300$ DPI) 